\title{
Dissociation of somatostatin and parvalbumin interneurons circuit dysfunctions underlying hippocampal theta and gamma oscillations impaired by amyloid $\beta$ oligomers in vivo
}

\author{
Hyowon Chung ${ }^{1} \cdot$ Kyerl Park $^{1} \cdot$ Hyun Jae Jang ${ }^{1} \cdot$ Michael M. Kohl ${ }^{2} \cdot$ Jeehyun Kwag $^{1}$ (])
}

Received: 28 June 2019 / Accepted: 6 February 2020 / Published online: 27 February 2020

(c) The Author(s) 2020

\begin{abstract}
Accumulation of amyloid $\beta$ oligomers $(\mathrm{A} \beta \mathrm{O})$ in Alzheimer's disease (AD) impairs hippocampal theta and gamma oscillations. These oscillations are important in memory functions and depend on distinct subtypes of hippocampal interneurons such as somatostatin-positive (SST) and parvalbumin-positive (PV) interneurons. Here, we investigated whether A $\beta \mathrm{O}$ causes dysfunctions in SST and PV interneurons by optogenetically manipulating them during theta and gamma oscillations in vivo in A $\beta O$-injected SST-Cre or PV-Cre mice. Hippocampal in vivo multi-electrode recordings revealed that optogenetic activation of channelrhodopsin-2 (ChR2)-expressing SST and PV interneurons in A $\beta O$-injected mice selectively restored A $\beta O-$ induced reduction of the peak power of theta and gamma oscillations, respectively, and resynchronized CA1 pyramidal cell (PC) spikes. Moreover, SST and PV interneuron spike phases were resynchronized relative to theta and gamma oscillations, respectively. Whole-cell voltage-clamp recordings in CA1 PC in ex vivo hippocampal slices from A $\beta \mathrm{O}$-injected mice revealed that optogenetic activation of SST and PV interneurons enhanced spontaneous inhibitory postsynaptic currents (IPSCs) selectively at theta and gamma frequencies, respectively. Furthermore, analyses of the stimulus-response curve, paired-pulse ratio, and short-term plasticity of SST and PV interneuron-evoked IPSCs ex vivo showed that A $\beta O$ increased the initial GABA release probability to depress SST/PV interneuron's inhibitory input to CA1 PC selectively at theta and gamma frequencies, respectively. Our results reveal frequency-specific and interneuron subtype-specific presynaptic dysfunctions of SST and PV interneurons' input to CA1 PC as the synaptic mechanisms underlying A $\beta O$-induced impairments of hippocampal network oscillations and identify them as potential therapeutic targets for restoring hippocampal network oscillations in early AD.
\end{abstract}

Keywords Hippocampus · Somatostatin interneuron · Parvalbumin interneuron · Amyloid beta oligomers · Network oscillations · Alzheimer's disease

Hyowon Chung and Kyerl Park contributed equally to this work.

Electronic supplementary material The online version of this article (https://doi.org/10.1007/s00429-020-02044-3) contains supplementary material, which is available to authorized users.

Jeehyun Kwag

jkwag@korea.ac.kr

1 Department of Brain and Cognitive Engineering, Korea University, Seoul, Korea

2 Department of Physiology, Anatomy and Genetics, University of Oxford, Oxford, UK

\section{Introduction}

Alzheimer's disease (AD) is a neurodegenerative condition characterized by progressive memory loss and cognitive decline (LaFerla et al. 2007; Selkoe 2002; Hardy and Selkoe 2002). Abnormal accumulation of amyloid $\beta$ oligomers $(\mathrm{A} \beta \mathrm{O})$ has been implicated in the pathogenesis of early stage AD (Hardy and Selkoe 2002; Lambert et al. 1998; Lesne et al. 2006; McLean et al. 1999; Walsh and Selkoe 2004), causing synaptic dysfunctions (Lacor et al. 2004; Shankar et al. 2007, 2008; Hsieh et al. 2006; Kamenetz et al. 2003) including impairments to synaptic plasticity (Lambert et al. 1998; Walsh and Selkoe 2004; Walsh et al. 2002) and ultimately neuronal death (Alberdi et al. 2010; De Felice et al. 2007; Decker et al. 2010). Similarly, transgenic mice that model A $\beta O$-related pathologies of AD (Wang et al. 2002; 
Iaccarino et al. 2016; Verret et al. 2012; Martinez-Losa et al. 2018; Tomiyama et al. 2010) show impairments to synaptic plasticity (Chapman et al. 1999; Rowan et al. 2003; Larson et al. 1999; Tomiyama et al. 2010) and memory functions (Brouillette et al. 2012; Kim et al. 2014; Tomiyama et al. 2010). Especially, hippocampal network oscillations, which are important for spatial information processing (O'Keefe and Recce 1993; Dragoi and Buzsaki 2006) and synaptic plasticity (Huerta and Lisman 1993; Bikbaev and ManahanVaughan 2008; Buzsaki 2002; Vertes 2005), are impaired in these animal models of AD (Driver et al. 2007; Iaccarino et al. 2016; Ittner et al. 2014; Mondragon-Rodriguez et al. 2018; Palop and Mucke 2016; Villette et al. 2010; Wang et al. 2002). Distinct subtypes of hippocampal interneurons are critically involved in hippocampal oscillogenesis (Huh et al. 2016; Mikulovic et al. 2018; Amilhon et al. 2015; Gulyas et al. 2010; Mann et al. 2005; Wang and Buzsaki 1996). Somatostatin-positive (SST) interneurons preferentially modulate theta oscillations (Mikulovic et al. 2018), while parvalbumin-positive (PV) interneurons modulate gamma oscillations (Iaccarino et al. 2016; Huh et al. 2016; Amilhon et al. 2015). In addition, SST interneurons such as oriens lacunosum-moleculare (O-LM) cells show enhanced responses to theta frequency inputs (Pike et al. 2000; Zemankovics et al. 2010; Whittington and Traub 2003), while PV interneurons such as basket cells show enhanced responses to gamma frequency inputs (Pike et al. 2000; Zemankovics et al. 2010), further indicating their cell type-specific involvement in theta and gamma oscillations. Recent experimental evidence revealed that SST and PV interneurons disintegrate structurally and functionally in mouse models of AD (Palop et al. 2007; Schmid et al. 2016; Chen et al. 2018; Verret et al. 2012; Martinez-Losa et al. 2018; Iaccarino et al. 2016), suggesting that dysfunctions of SST and PV interneurons may underlie impairments of theta and gamma oscillations observed in AD. Optogenetic activation (Iaccarino et al. 2016) or molecular manipulation (Martinez-Losa et al. 2018; Zhang et al. 2017) of PV interneurons could restore impaired hippocampal gamma oscillations in mouse models of AD. However, the relative contribution of SST and PV interneurons to the impairments of hippocampal theta and gamma oscillations observed in AD remains unknown.

To address this, we optogenetically manipulated the activity of SST or PV interneurons in an $\mathrm{A} \beta \mathrm{O}$-injected mouse model of $\mathrm{AD}$. We found that $\mathrm{A} \beta \mathrm{O}$ injections into the hippocampus reduced the peak powers of theta and gamma oscillations and desynchronized the spike phases of CA1 pyramidal cells (PCs) relative to both theta and gamma cycles. Optogenetic activation of ChR2-expressing SST and PV interneurons selectively restored the peak power of theta and gamma oscillations, respectively, to the levels observed in the control mice, and resynchronized CA1 PC spike phases. Further analyses revealed that spike phases of SST and PV interneurons in A $\beta \mathrm{O}$-injected mice were also resynchronized selectively relative to theta and gamma oscillations, respectively. Ex vivo whole-cell voltage-clamp recordings in CA1 PC in acute hippocampal slices from A $\beta O$-injected mice revealed that sustained optogenetic activation of SST and PV interneurons selectively enhanced spontaneous inhibitory postsynaptic currents (sIPSCs) onto CA1 PC at theta and gamma frequencies, respectively. Investigating the $\mathrm{A} \beta \mathrm{O}$-induced changes at the synaptic level through analyzing the stimulus-response $(S-R)$ curve, paired-pulse ratio, and short-term plasticity revealed that $\mathrm{A} \beta \mathrm{O}$ increased the initial GABA release probability resulting in the depression of SST and PV interneuron-evoked inhibitory postsynaptic currents (IPSCs) selectively at $5 \mathrm{~Hz}$ and $40 \mathrm{~Hz}$, respectively. Together, these results suggest that interneuron subtype-specific and frequency-specific presynaptic dysfunctions of SST and PV interneurons' inhibitory inputs to CA1 PC may underpin the impairment of theta and gamma oscillations in $\mathrm{A} \beta \mathrm{O}$-injected mice in vivo.

\section{Materials and methods}

\section{Animals}

All experimental animals were obtained from Jackson Laboratory (SST-IRES-Cre knock-in mice: stock no. 013044, PV-Cre knock-in mice: stock no. 017320, Jackson Laboratory, Bar Harbor, ME, USA) (Taniguchi et al. 2011). Mice were housed in a temperature-controlled environment under a 12:12 h light-dark cycle with food and water provided ad libitum. All experimental procedures were approved by the Institutional Animal Care and Use Committee (IACUC) of Korea University (KUIACUC-2017-112 and KUIACUC-2019-0068).

\section{Soluble $A \beta O$ preparation}

Soluble A $\beta O$ was prepared following the methods described in (Lambert et al. 1998) with slight modification in $A \beta$ oligomerization (Park et al. 2020). Soluble $A \beta_{1-42}$ (Bechem) monomerization was achieved by dissolving it in 1,1,1,3,3,3-hexafluoro-2-propanol (HFIP, Sigma Aldrich) at a final concentration of $1 \mathrm{mM}$. The HFIP-A $\beta_{1-42}$ solution was incubated at room temperature (90 $\mathrm{min}$ ) and HFIP was evaporated using a vacuum evaporator (SpeedVac, $\mathrm{N}-\mathrm{BIOTEK}$ Inc.). The remaining monomerized $\mathrm{A} \beta_{1-42}$ film was dissolved in dimethyl sulfoxide (DMSO, Sigma Aldrich) to make $50 \mu \mathrm{M} \mathrm{A} \beta_{1-42}$ stock. $\mathrm{A} \beta_{1-42}$ stock was aliquoted and stored at $-20{ }^{\circ} \mathrm{C}$. One day before $\mathrm{A} \beta \mathrm{O}$ injection surgery, the $\mathrm{A} \beta_{1-42}$ stock was thawed and diluted to a final concentration of $10 \mu \mathrm{M}$ in PBS. After dilution, $\mathrm{A} \beta_{1-42}$ solution was incubated for $18 \mathrm{~h}$ for $\mathrm{A} \beta$ oligomerization. 


\section{Stereotaxic surgery}

To express channelrhodopsin-2 (ChR2) in SST or PV interneurons, we injected adeno-associated virus (AAV) (AAV5-EF1a-DIO-hChR2(E123T/T159C)-p2A-mCherryWPRE, $3.8 \times 10^{12}$ virus molecules $/ \mathrm{mL}, 1 \mu \mathrm{L}$, UNC Vector Core) into the CA1 region of the hippocampus in SST-Cre and PV-Cre mice (postnatal day 28-49). AAV was injected unilaterally into the CA1 region of the left hippocampus (2.7 $\mathrm{mm}$ posterior, $2.7 \mathrm{~mm}$ lateral and $1.85 \mathrm{~mm}$ ventral from the bregma) using a $5 \mu \mathrm{L}$ micro-needle (Hamilton Company) connected to a motorized stereotaxic injector (delivery rate: $0.1 \mu \mathrm{L} / \mathrm{min}$ ). Then, either DMSO (diluted in PBS, $3 \mu \mathrm{L}$, delivery rate: $0.3 \mu \mathrm{L} / \mathrm{min})$ or soluble $\mathrm{A} \beta \mathrm{O}(3 \mu \mathrm{L}$, delivery rate: $0.3 \mu \mathrm{L} / \mathrm{min}$ ) was co-injected to the same location to create control mice or mice with $\mathrm{A} \beta \mathrm{O}$ pathology, respectively (Fig. 1a). To establish whether there is a difference between unilateral and bilateral hippocampal injections of $A \beta O$ on hippocampal local field potentials (LFPs), we injected $A \beta O$ in CA1 region of the hippocampus bilaterally as well (Online resource Fig. 1). The needle was left in the brain for $>5 \mathrm{~min}$ to minimize backflow of the injection. Body temperature was maintained using a heating pad during surgery. At least 3 weeks of recovery period was allowed after surgery before in vivo or ex vivo experiments to ensure the proper expression of the virus and induction of $A \beta O$ pathology (Villette et al. 2010).

\section{Hippocampal in vivo recording}

In vivo LFPs and single unit recordings were made in anesthetized mice [ketamine $(75-100 \mathrm{mg} / \mathrm{kg}$ ), medetomidine $(1 \mathrm{mg} / \mathrm{kg})]$, head-fixed into a stereotaxic frame, using a 32-channel silicon probe (A1x32-Poly2-5mm-50s-177, Neuronexus) inserted into the hippocampal CA1 region $(2.7 \mathrm{~mm}$ posterior, $2.7 \mathrm{~mm}$ lateral from bregma, and $1.85 \mathrm{~mm}$ ventral from the pia) (Fig. 1e). Extracellular signals were sampled at $25 \mathrm{kHz}$ for single unit acquisition and then down-sampled to $1 \mathrm{kHz}$ for LFP acquisition (RZ2, Tucker-Davis Technologies). For the optogenetic activation of SST or PV interneurons, blue LED light stimulation $(473 \mathrm{~nm}, 50 \%$ of maximum intensity, X-Cite 110LED, Excelitas Technologies) was delivered via an optical fiber laminated to the 32-channel silicon probe ( $3 \mathrm{~s}$, inter-trial interval of $60 \mathrm{~s}, 10$ repetitions) (Fig. 1e). Body temperature was monitored and maintained at $37^{\circ} \mathrm{C}$ throughout the experiments.

\section{Immunohistochemistry}

To determine the position of each electrode within the hippocampal subregions, the silicon probe was removed from the hippocampus after the in vivo recording and coated with a fluorescent dye (Alexa 594). Alexa 594-coated silicon probe was re-inserted to the same coordinates in the hippocampus at least for $1 \mathrm{~min}$. Mice were then perfused with ice-cold cutting solution [(in $\mathrm{mM}$ ): 180 sucrose, $2.5 \mathrm{KCl}$, $1.25 \mathrm{NaH}_{2} \mathrm{PO}_{4}, 25 \mathrm{NaHCO}_{3}, 11$ glucose, $2 \mathrm{MgSO}_{4}$, and 1 $\mathrm{CaCl}_{2}$ (pH 7.2-7.4, 280-290 mOsm, and oxygenated with $\left.95 \% \mathrm{O}_{2} / 5 \% \mathrm{CO}_{2}\right)$ ], after which the removed mice brain was cut into $300 \mu \mathrm{m}$ hippocampal slices in ice-cold cutting solution using a vibratome (VT 1000 S, Leica Microsystems) and fixed in $4 \%$ paraformaldehyde (PFA, Sigma-Aldrich) for $>24 \mathrm{~h}$ at $4{ }^{\circ} \mathrm{C}$. Fixed slices were rinsed in wash buffer three times ( $0.3 \%$ Triton X-100 in 0.1 M PBS) and mounted on glass slides. Fluorescent signal of Alexa 594 was visualized using a fluorescent microscope (Leica DM2500, Fig. 1f). To verify the deposition of $A \beta O$ in the hippocampal CA1 region, PFA-fixed hippocampal slices were incubated in peroxidase buffer $\left(0.3 \% \mathrm{H}_{2} \mathrm{O}_{2}\right.$ in $0.1 \mathrm{M}$ PBS $)$ for $20 \mathrm{~min}$. Non-targeted antigens were blocked by incubation in $6 \%$ bovine serum albumin and $0.3 \%$ Triton X-100 in $0.1 \mathrm{M}$ PBS for $>24 \mathrm{~h}$ at $4{ }^{\circ} \mathrm{C}$, after which slices were incubated with primary antibody (anti-beta amyloid 1-42 antibody [mOC64]-Conformation-Specific, Abcam, 1:300 dilution in $0.1 \mathrm{M}$ PBS, at $4{ }^{\circ} \mathrm{C}$ for 4 days) and secondary antibody $\left(\mathrm{Cy}^{\mathrm{TM}_{3}}\right.$ AffiniPure Donkey Anti-Rabbit IgG $(\mathrm{H}+\mathrm{L})$, Jackson ImmunoResearch, 1:500 dilution in 0.1 M PBS). Slices were washed and mounted on slide glasses with cubic mount (Lee et al. 2016) to clear the tissue. Immuno-stained $A \beta O$ in the hippocampal slices were visualized with the fluorescent microscope (Leica DM2500, Fig. 1b). Expression of ChR2 in SST and PV interneurons was verified by detecting the fluorescent signal of the fused mCherry reporter using the fluorescent microscope (DM2500, Leica) or confocal microscope (LSM-700, ZEISS, Fig. 1c, d).

\section{Data analysis of in vivo LFPs and spikes}

LFP signals were common-average filtered at $1-500 \mathrm{~Hz}$, after which a fast Fourier transform (FFT) was performed to analyze the power spectral density (PSD) of unfiltered LFPs (Figs. 1n, 2g; Online resource Figs. 1, 3, 4). Peak frequencies and peak powers of delta $(1-3 \mathrm{~Hz})$, theta $(3-12 \mathrm{~Hz})$, beta $(13-30 \mathrm{~Hz})$, and gamma oscillations $(30-60 \mathrm{~Hz})$ were characterized from the PSD of unfiltered LFPs at each frequency band (Figs. 1o-r, 2h-k; Online resource Figs. 1-4). Power spectrograms of theta and gamma oscillations were plotted by taking short-time Fourier transform to the third order butterworth bandpass filters $(3-12 \mathrm{~Hz}$ for theta and 30-60 Hz for gamma oscillations, Figs. 1h-m, 2a-f; Online resource Figs. 1, 3, 4). Spikes were extracted from 300 to $5000 \mathrm{~Hz}$ band-pass filtered extracellular signals using the Klusta-suite software (Rossant et al. 2016). Spike waveform, inter-spike intervals, and the shape of auto-correlogram of spike times were examined to refine single unit identification (Hill et al. 2011). Classification of putative CA1 PCs 
a

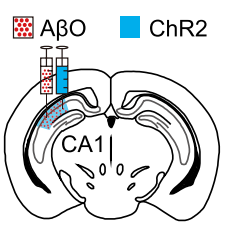

e

Blue light
$(473 \mathrm{~nm})$ (n vivo

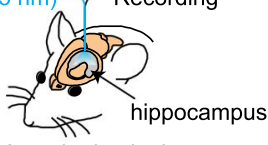

Anesthetized mice b

Hippocampal slice

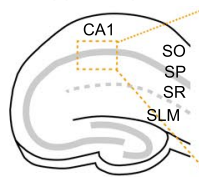

f

Electrode location

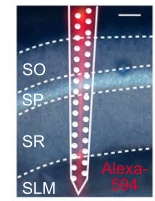

Theta oscillations

h DMSO-injected SST-Cre mice

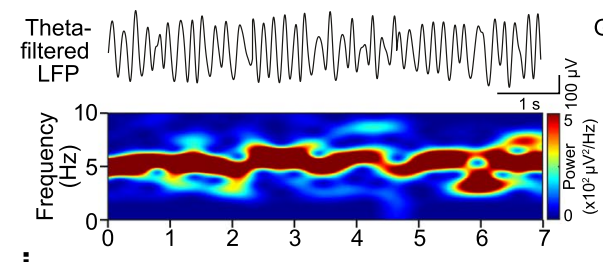

j

ThetaA $\beta O$-injected SST-Cre mice

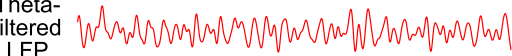

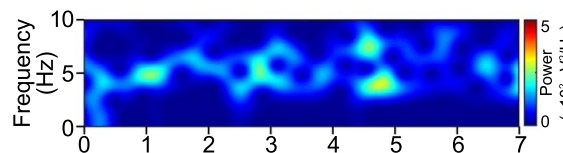

I ABO-injected SST-Cre mice + SST activation

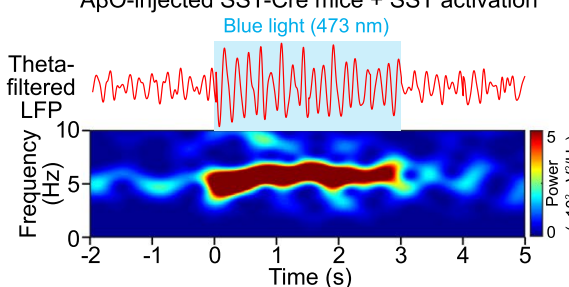

C

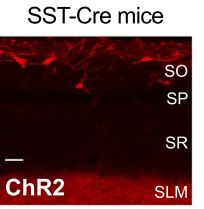

d PV-Cre mice

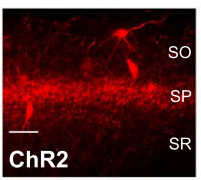

DMSO-injected mice g

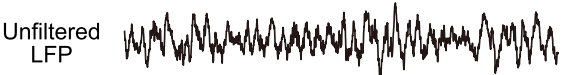

AßO-injected mice

Unfiltered AFP
LFP
Gamma oscillations

i DMSO-injected SST-Cre mice

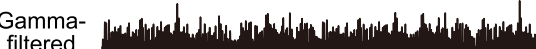

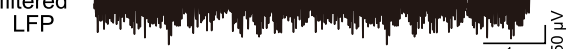

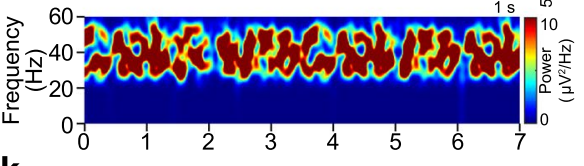

k

A OO-injected SST-Cre mice

Gamma-

filtered

LFP

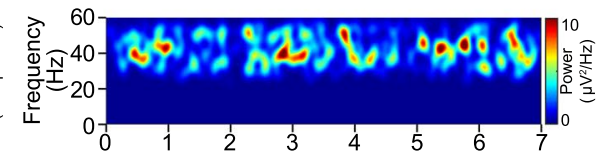

m ABO-injected SST-Cre mice + SST activation Blue light $(473 \mathrm{~nm})$

Gamma-

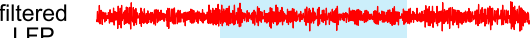
LFP
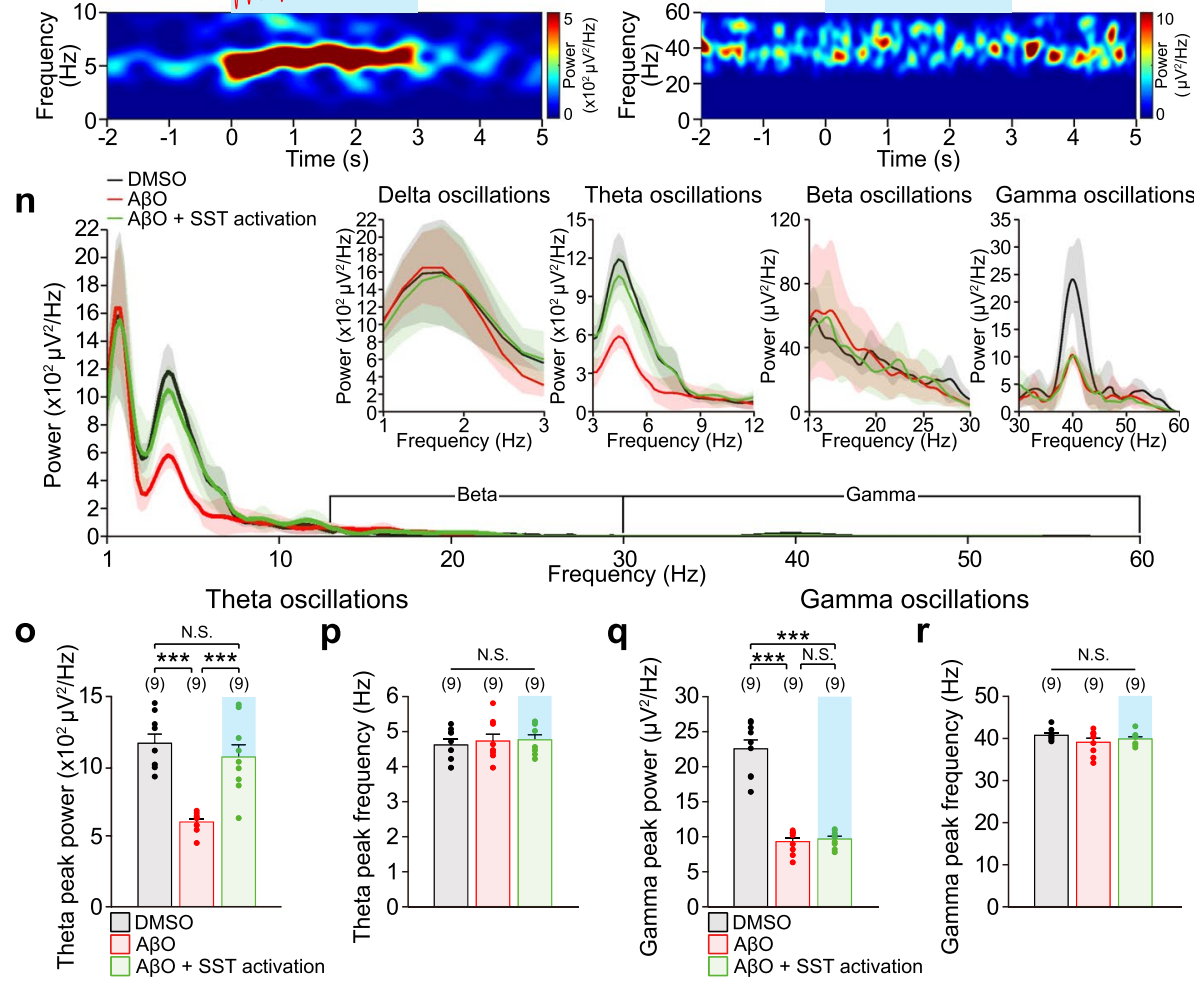
४Fig. 1 Optogenetic activation of SST interneurons selectively restores hippocampal theta oscillations impaired in $\mathrm{A} \beta \mathrm{O}$-injected mice in vivo. a Schematic illustration of $A \beta O$ and ChR2-carrying AAV virus injection into hippocampal CA1 region unilaterally. b Left, schematic illustration of hippocampus structure. Right, immunochemistry showing deposition of $A \beta O$ in sub-layers of CA1 (SO: stratum oriens, SP: stratum pyramidale, SR: stratum radiatum, SLM: stratum lacunosum-moleculare). Scale bar: $100 \mu \mathrm{m}$. Fluorescence image of ChR2-expressing SST interneurons in A $\beta O$-injected SSTCre mice (c) and PV interneurons in A $\beta \mathrm{O}$-injected PV-Cre mice (d). Scale bars: $100 \mu \mathrm{m}$. e Schematic illustration of in vivo recording and blue light $(473 \mathrm{~nm})$ stimulation in CA1 region of the hippocampus in anesthetized mice. f Position of the 32-channel silicon probe in CA1 region. Alexa 594 fluorescent dye-stained probe track identified the sub-layers of CA1. Signals from SP were used for LFP analysis. Scale bar $100 \mu \mathrm{m}$. g Representative traces of unfiltered LFPs recorded in DMSO-injected (top, black trace) and A $\beta O$-injected SST-Cre mice (bottom, red trace). Representative traces of band-pass filtered LFPs (top) at theta (h) and gamma frequency (i) and the corresponding power spectrograms (bottom) recorded from DMSO-injected SSTCre mice. $\mathbf{j}$, $\mathbf{k}$ Same as $\mathbf{h}, \mathbf{i}$ but in A $\beta O$-injected SST-Cre mice. $\mathbf{l}, \mathbf{m}$ Same as $\mathbf{h}$, $\mathbf{i}$ but with blue light stimulation of ChR2-expressing SST interneuron in A $\beta \mathrm{O}$-injected SST-Cre mice. $\mathbf{n}$ Power spectral density (PSD) of unfiltered LFPs (shade indicates SEM) recorded in DMSOinjected SST-Cre mice ( $n=9$, black), A $\beta O$-injected SST-Cre mice $(n=9$, red), and with blue light stimulation of ChR2-expressing SST interneuron in $\mathrm{A} \beta \mathrm{O}$-injected SST-Cre mice ( $n=9$, green). Insets show PSD of unfiltered LFPs in delta, theta, beta, and gamma frequencyranges. Mean peak power (o) and mean peak frequency (p) of theta oscillations analyzed from the PSD of each condition in $\mathbf{n} . \mathbf{q}, \mathbf{r}$ Same as $\mathbf{0}, \mathbf{p}$ but for gamma oscillations in each condition. $n$ The number of animals from which LFPs were recorded. One-way ANOVA followed by Tukey's post hoc test $(\mathbf{o}-\mathbf{r} * * * p<0.001$, N.S. $p>0.05)$. Data are mean \pm SEM with individual data values (dots)

and putative CA1 interneurons were based on spike waveform asymmetry index $\{[(b-a) /(b+a)]$, baseline-to-peak amplitude $(a)$, last baseline-to-peak amplitude $(b)\}$ to the trough-to-peak latency $(c)$. Neurons located on the right of the decision boundary $([(b-a) /(b+a)]=2 \times c-1.2)$ were considered putative CA1 PCs (Fig. 3a). Putative CA1 interneurons that showed increased firing rates in response to blue light stimulation in SST-Cre or PV-Cre mice in the peristimulus time histogram (PSTH, $100 \mathrm{~ms}$ bin) were identified as putative SST or PV interneurons, respectively (Fig. 3b). Oscillation cycles were analyzed using the Hilbert transform and the spike times of each neuronal types were used to calculate the spike phases relative to theta or gamma cycles (Khodagholy et al. 2017; Tort et al. 2010). The probability distribution of spike phases was analyzed through normalizing the spike phases in each 36-degree bin by the total number of spikes (Figs. 3c, g, 4a, e, i, m). Each spike phase probability was vectorized on the polar coordinate (Figs. 3d, $\mathrm{h}, 4 \mathrm{~b}, \mathrm{f}, \mathrm{j}, \mathrm{n})$. The mean spike phases were analyzed using the Circular Statistics Toolbox in MATLAB (Berens 2009) (Figs. 3e, i, 4c, g, k, o). The strength of phase-locking was analyzed by calculating the mean vector length of the spike phases on the polar coordinate (Figs. 3f, j, 4d, h, l, p) (Zar
1999). All LFP signals were analyzed using customized protocols in MATLAB (R2018a).

\section{Brain slice preparation for ex vivo recording}

After 3 weeks following co-injection of $\mathrm{A} \beta \mathrm{O}$ and $\mathrm{ChR} 2-$ carrying AAV, mice were anesthetized with $1.25 \%$ avertin solution (8 $\mathrm{g}$ of 2,2,2-tribromoethanol, $5.1 \mathrm{~mL}$ of 2-methyl2-butanol and $402.9 \mathrm{~mL}$ saline, Sigma Aldrich) and perfused with ice-cold cutting solution, after which the brain was rapidly removed into oxygenated ice-cold cutting solution. Coronal hippocampal slices $(300 \mu \mathrm{m})$ were cut using a vibratome and allowed to recover for $20 \mathrm{~min}$ in a solution which was made up of a mixture of cutting solution and artificial cerebro spinal fluid (aCSF) [(in mM): $126 \mathrm{NaCl}, 3$ $\mathrm{KCl}, 1.25 \mathrm{NaH}_{2} \mathrm{PO}_{4}, 2 \mathrm{MgSO}_{4}, 2 \mathrm{CaCl}_{2}, 25 \mathrm{NaHCO}_{3}$, and 10 glucose (pH 7.2-7.4, 280-290 mOsm, and oxygenated with $\left.95 \% \mathrm{O}_{2} / 5 \% \mathrm{CO}_{2}\right)$ ] at 1:1 ratio. Slices were further incubated in oxygenated aCSF solution for at least $1 \mathrm{~h}$ at $30-32{ }^{\circ} \mathrm{C}$ before being transferred to the recording chamber.

\section{Ex vivo whole-cell patch-clamp recordings}

For ex vivo experiments, slices were moved to a recording chamber filled with aCSF at $30-32{ }^{\circ} \mathrm{C}$. Whole-cell voltageclamp recordings were performed on visually identified CA1 PC (BW51W, Olympus) using a borosilicate glass electrode (4-8 M $\Omega$ ) filled with intracellular solution [(in $\mathrm{mM}$ ): 115 cesium methanesulfonate, $8 \mathrm{NaCl}, 10$ HEPES, 0.3 $\mathrm{Na}_{3}$-GTP, 4 Mg-ATP, 0.3 EGTA, 5 QX-314, and 10 BAPTA (pH 7.3-7.4 and 280-290 mOsm)]. 10 min was allowed after break-through for stabilization before recordings commenced. Series resistance was monitored throughout the experiment and cells with $>20 \%$ change in series resistance over the course of the recording were discarded. IPSCs were recorded through voltage-clamp recordings from CA1 PC at a holding potential of $+10 \mathrm{mV}$. To record sIPSCs during sustained optogenetic activation of SST or PV interneurons, $3 \mathrm{~s}$-long sustained blue light stimulation $(470 \mathrm{~nm}$, inter-trial interval of $60 \mathrm{~s}, 15 \mathrm{~mW}$ ) was delivered (Figs. 5, 6; Online resource Fig. 5) using a digital micromirror device (DMD, Polygon400, Mightex). Detection threshold of sIPSCs was set at $10 \mathrm{pA}$, which was three-fold greater than the baseline noise standard deviation. Detection and analysis of sIPSCs were performed using customized MATLAB code. For power spectral analysis, sIPSCs were first down-sampled to $1 \mathrm{kHz}$ before a band-pass filter was applied (3-12 $\mathrm{Hz}$ for theta frequency and $30-60 \mathrm{~Hz}$ for gamma frequency). Then, FFT was performed to analyze the PSD, from which the peak frequencies and the peak powers were characterized (Fig. 5h, i, 1, m; Online resource Fig. 5f, g, j, k). Spectrograms of band-pass filtered sIPSCs at both theta and gamma frequencies were generated using a short-time Fourier 
Theta oscillations

a
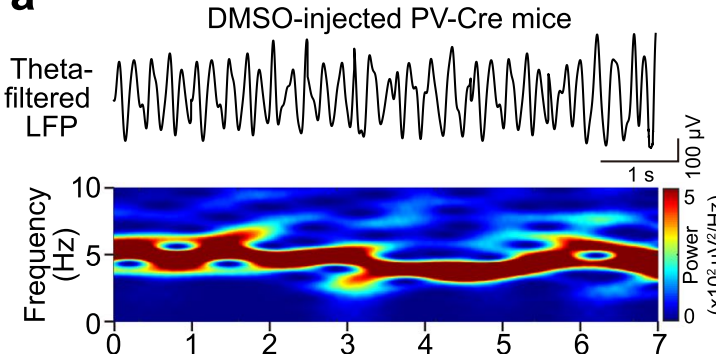

C

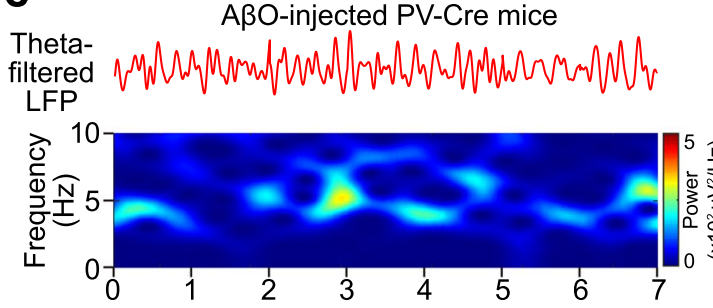

e

$\mathrm{A} \beta \mathrm{O}$-injected $\mathrm{PV}-\mathrm{Cre}$ mice + PV activation Blue light $(473 \mathrm{~nm})$

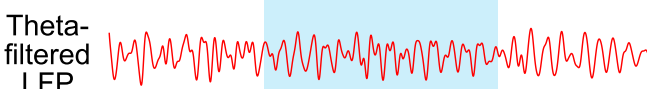

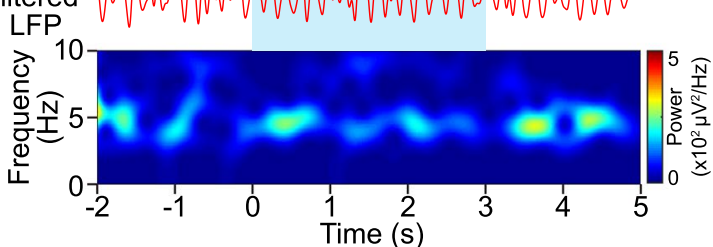

b

Gamma oscillations

DMSO-injected PV-Cre mice

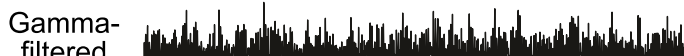

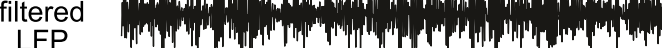
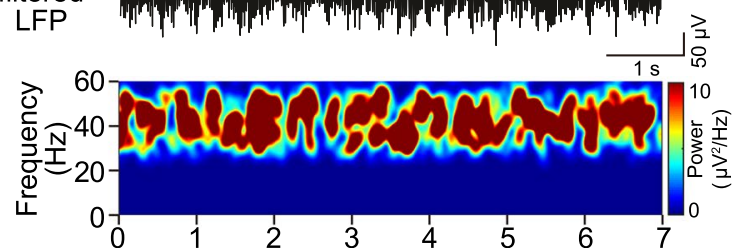

d

AßO-injected PV-Cre mice

Gamma-

LFP

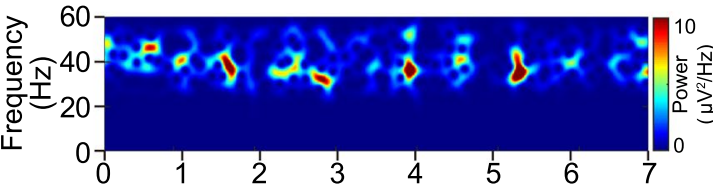

f

ABO-injected PV-Cre mice + PV activation Blue light $(473 \mathrm{~nm})$

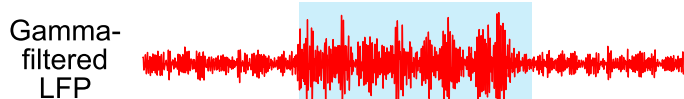

LFP

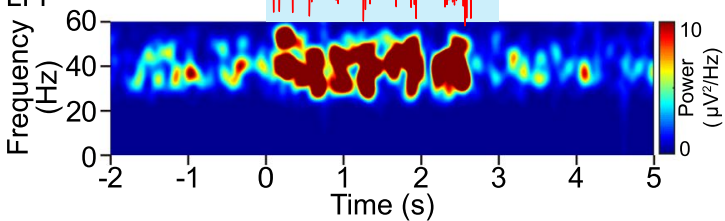

g Delta oscillations Theta oscillations Beta oscillations Gamma oscillations
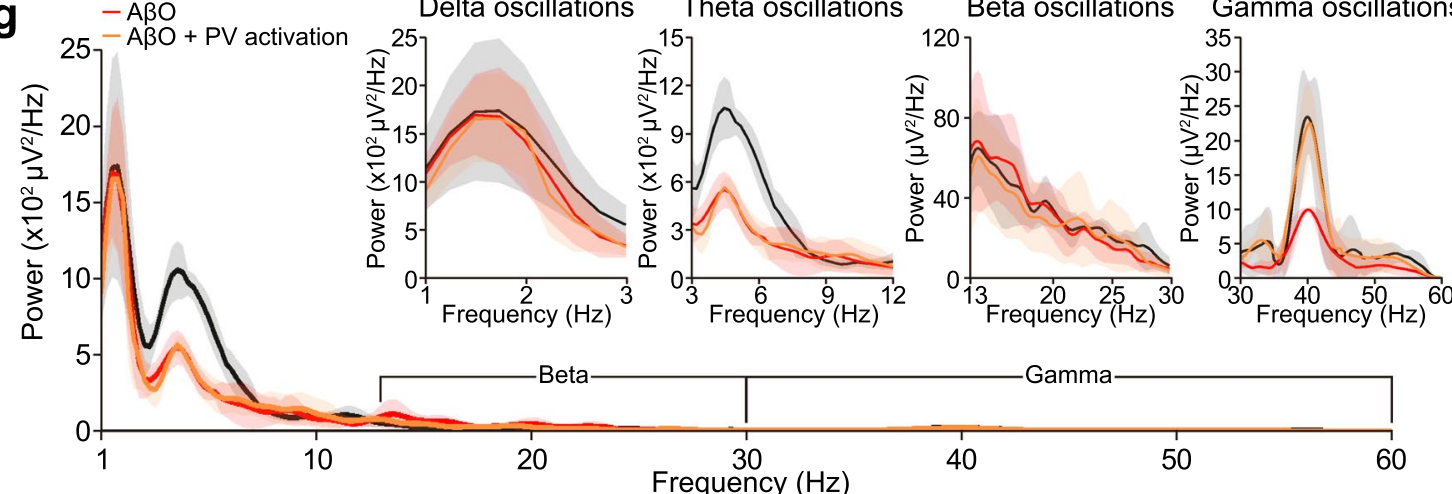

Theta oscillations

h

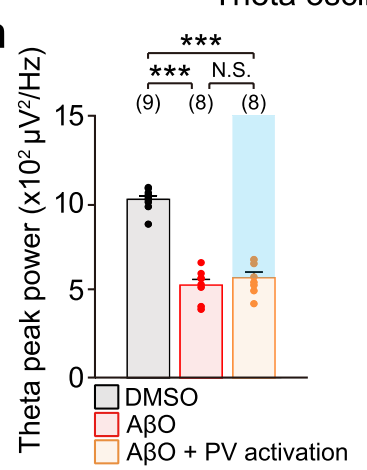

i

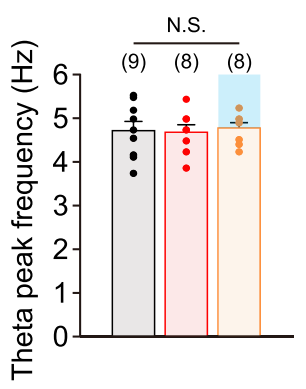

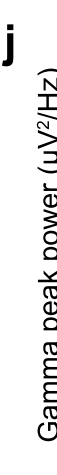

Gamma oscillations
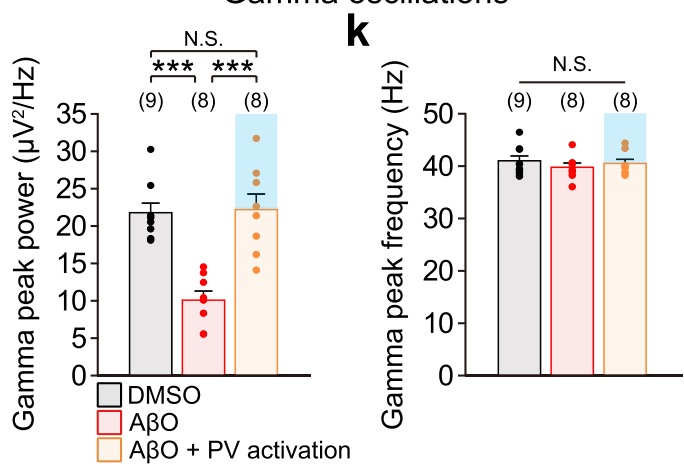
४Fig. 2 Optogenetic activation of PV interneurons restores hippocampal gamma oscillations impaired in $\mathrm{A} \beta \mathrm{O}$-injected mice in vivo. Representative traces of band-pass filtered LFPs (top) at theta (a) and gamma frequency (b) and corresponding power spectrograms (bottom) recorded from DMSO-injected PV-Cre mice. c, d Same as $\mathbf{a}, \mathbf{b}$ but in A $\beta O$-injected PV-Cre mice. e, $\mathbf{f}$ Same as $\mathbf{a}, \mathbf{b}$ but with blue light $(473 \mathrm{~nm})$ stimulation (blue shade) of ChR2-expressing PV interneurons in $\mathrm{A} \beta \mathrm{O}$-injected $\mathrm{PV}-\mathrm{Cre}$ mice. $\mathrm{g}$ Power spectral density (PSD) of unfiltered LFPs (shade indicates SEM) recorded in DMSOinjected PV-Cre mice ( $n=9$, black), A $\beta O$-injected PV-Cre mice $(n=8$, red), and with blue light stimulation of ChR2-expressing PV interneuron in $\mathrm{A} \beta \mathrm{O}$-injected $\mathrm{PV}-\mathrm{Cre}$ mice $(n=8$, orange). Insets show PSD of unfiltered LFPs in delta, theta, beta, and gamma frequencyranges. Mean peak power (h) and mean peak frequency (i) of theta oscillations analyzed from the PSD of each condition in $\mathbf{g}$. $\mathbf{j}, \mathbf{k}$ Same as $\mathbf{h}, \mathbf{i}$ but those of gamma oscillations in each condition. $n$ The number of animals from which LFPs were recorded. One-way ANOVA followed by Tukey's post hoc test (h-k $* * * p<0.001$, N.S. $p>0.05)$. Data are mean \pm SEM with individual data values (dots)

transform. To avoid light stimulation-induced artifacts, the first $1 \mathrm{~s}$ of sIPSCs during sustained optogenetic activation of SST or PV interneurons was not included in the power analysis. To analyze the $S-R$ curve of SST interneuron- and PV interneuron-evoked IPSCs (Fig. 6b, d), a single blue light pulse $(470 \mathrm{~nm}, 5 \mathrm{~ms})$ with different stimulation intensities $[5,10,25,50,75$, and $100 \%$ of maximal light power $(15 \mathrm{~mW})]$ was delivered to either ChR2-expressing SST or $\mathrm{PV}$ interneurons and the corresponding evoked IPSCs were recorded from CA1 PC. For the subsequent paired-pulse ratio (PPR) and short-term plasticity analysis (Fig. 6e-1), a train of ten blue light pulses $(470 \mathrm{~nm}, 5 \mathrm{~ms})$ with stimulation intensity that gave the half-maximal IPSC response in the $S-R$ curve (3-9 $\mathrm{mW}$ ) was delivered at either 5 or $40 \mathrm{~Hz}$ using DMD. PPR was calculated by normalizing the second evoked-IPSC by the first evoked-IPSC in the train (Fig. 6f, $\mathrm{h}, \mathrm{j}, \mathrm{l}$, left). Short-term plasticity was analyzed by normalizing the evoked-IPSCs in the train to the first evoked-IPSC (Fig. 6f, h, j, 1, right). All signals were amplified (MultiClamp 700B amplifier, Molecular Devices), low-pass filtered at $10 \mathrm{kHz}$, and acquired at $5 \mathrm{kHz}$ using the ITC-18 data acquisition interface (HEKA Elektronik). Igor Pro software (WaveMetrics) was used for generating command signals, acquiring data as well as data analysis.

\section{Statistical analysis}

Data are represented as mean \pm standard error of the mean (SEM). Statistical tests include one-way or two-way ANOVA followed by Tukey's post hoc test and Student's $t$ test. Statistical tests for spike phases were performed using WatsonWilliams multi-sample circular test (Zar 1989). Statistical analyses were performed with either SPSS or MATLAB.

\section{Results}

\section{Optogenetic activation of SST interneurons selectively restores hippocampal theta oscillations impaired in A $\beta O$-injected mice}

To investigate the relative contribution of SST and PV interneurons to the impairment of hippocampal theta and gamma oscillations in $\mathrm{AD}$, we created an $\mathrm{AD}$ mouse model by injecting A $\beta O$ (Villette et al. 2010; Stephan et al. 2003, 2001; Walsh et al. 2002; Meyer-Luehmann et al. 2006) and co-injecting an AAV virus containing a Cre-dependent ChR2 (AAV5-Ef1a-DIO-hChR2(ET/TC)-mCherry) into hippocampal CA1 region unilaterally (Fig. 1a) as well as bilaterally (Online resource Fig. 1) in either SST-Cre or PV-Cre mice. This enabled us to selectively modulate ChR2-expressing SST or PV interneurons in mice with $\mathrm{A} \beta \mathrm{O}$ pathology in vivo. Three weeks after injection, $\mathrm{A} \beta \mathrm{O}$ deposits were detectable in the CA1 region (Fig. 1b) and ChR2 was expressed in SST and PV interneurons in A $\beta O$ injected SST-Cre (Fig. 1c) and PV-Cre mice (Fig. 1d). In these mice expressing $\mathrm{A} \beta \mathrm{O}$ and $\mathrm{ChR} 2 \mathrm{~s}$, we performed LFP recordings of the hippocampus in vivo using a silicon probe laminated with an optical fiber for delivering blue light $(473 \mathrm{~nm})$ to the recording site (Fig. 1e). LFP recordings were analyzed for neurons recorded in the stratum pyramidale (SP) layer of the hippocampus (Fig. 1f).

First, we investigated the contribution of SST interneurons to $\mathrm{A} \beta \mathrm{O}$-induced impairment of hippocampal theta and gamma oscillations in SST-Cre mice. The raw LFPs recorded from DMSO-injected (Fig. 1g, top) and A $\beta O$ injected SST-Cre mice (Fig. 1g, bottom) were bandpass filtered at theta $(3-12 \mathrm{~Hz})$ and gamma frequencies (30-60 Hz), after which the corresponding spectrograms were plotted, which revealed that the powers of both theta and gamma oscillations were reduced in $\mathrm{A} \beta \mathrm{O}$-injected SST-Cre mice compared to those in DMSO-injected SSTCre mice (Fig. 1h-k). Similar reductions in the powers of theta and gamma oscillations were observed in mice that were injected with $\mathrm{A} \beta \mathrm{O}$ in the hippocampus bilaterally (Online resource Fig. 1). In contrast, we found that $\mathrm{A} \beta \mathrm{O}$ had no effect on the powers of delta $(1-3 \mathrm{~Hz})$ and beta oscillations (13-30 Hz; Online resource Fig. 2), indicating that the $\mathrm{A} \beta \mathrm{O}$-induced impairments were specific to theta and gamma oscillations. After confirming that the A $\beta O$-injected mice model can reliably replicate hippocampal theta and gamma oscillation impairments as observed in other studies AD (Driver et al. 2007; Iaccarino et al. 2016; Ittner et al. 2014; Mondragon-Rodriguez et al. 2018; Palop and Mucke 2016; Villette et al. 2010; Wang et al. 2002), we next investigated the effect of optogenetic activation of SST interneurons on theta and gamma 
a

Spike waveform of CA1 pyramidal cell
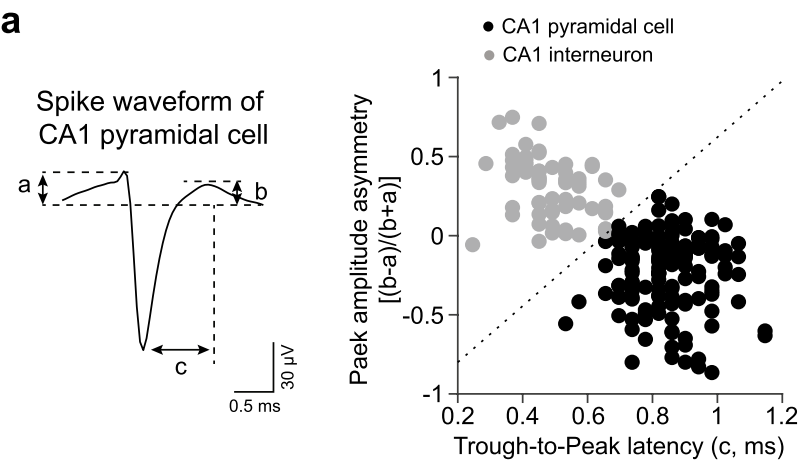

Theta oscillations

C
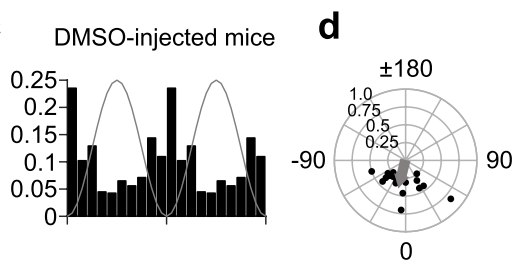

AßO-injected mice
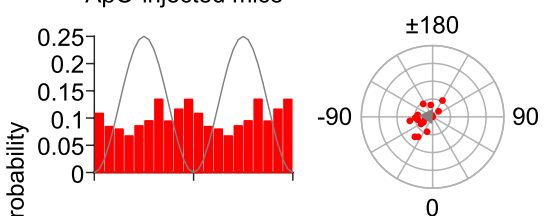

A $\mathrm{A} O$-injected SST-Cre mice
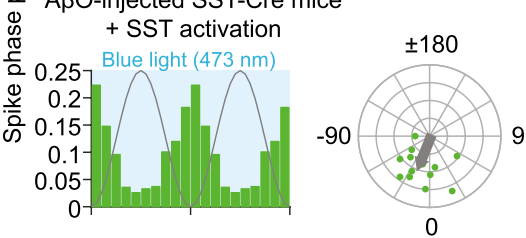

A $\beta O$-injected PV-Cre mice
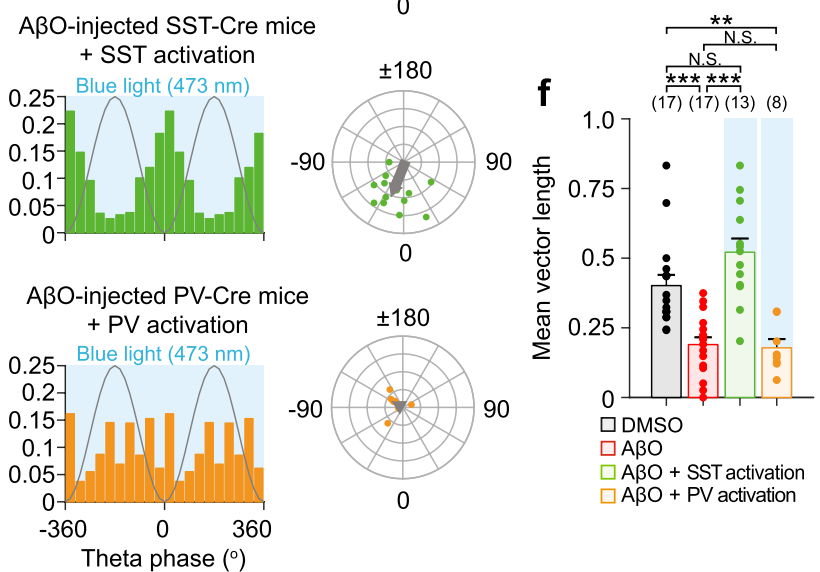

Fig. 3 Optogenetic activation of SST and PV interneurons resynchronizes CA1 PC spike phases relative to theta and gamma oscillations, respectively, in A $\beta \mathrm{O}$-injected mice in vivo. a Left, spike waveform analysis by calculating the early $(a)$ and late part of $(b)$ baseline-topeak amplitude and trough-to-peak latency $(c)$. Right, classification of single units into putative CA1 pyramidal cell (PC, black) and putative CA1 interneuron (gray) based on peak amplitude asymmetry $[(b-a) /(b+a)]$ plotted as a function of $c$. Dashed line is the decision boundary for determining putative CA1 PC (right) and putative CA1 interneuron (left). b Spike raster plot (top) and peri-stimulus time histogram (PSTH, bottom) of ChR2-expressing SST (left, green) and ChR2-expressing PV interneuron (right, orange) in response to blue light $(473 \mathrm{~nm})$ stimulation (blue shade). The probability distribution of CA1 PC spike phases relative to theta oscillations (c) and polar plot of resultant vector phase/vector length (d, filled circles) and the mean resultant vectors (d, gray arrow) analyzed from theta phase
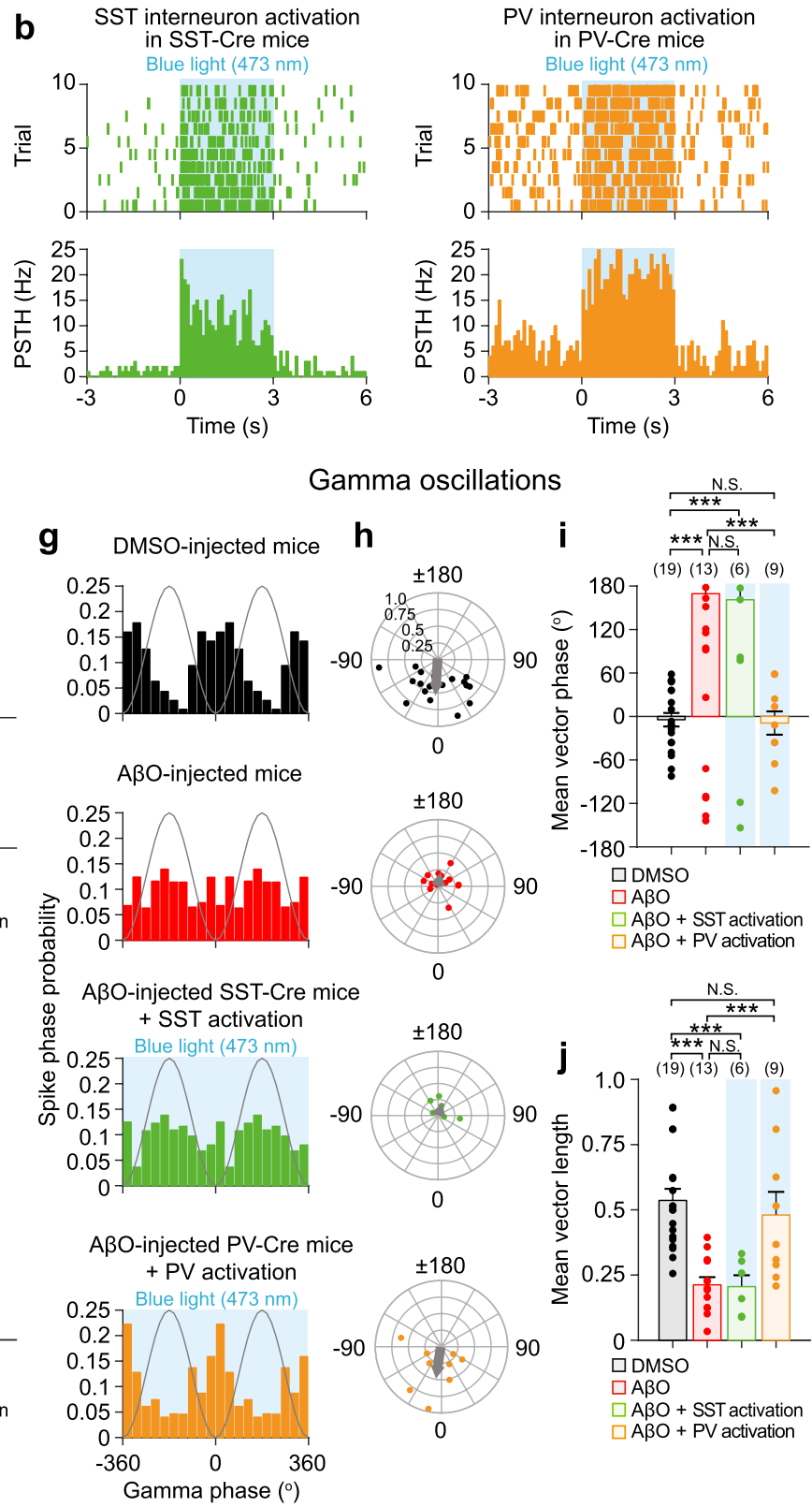

distribution of individual CA1 PC in DMSO-injected mice $(n=17$, black), A $\beta O$-injected mice ( $n=17$, red), with blue light stimulation of ChR2-expressing SST interneuron in A $\beta O$-injected SST-Cre mice ( $n=13$, green), and with blue light stimulation of ChR2-expressing $\mathrm{PV}$ interneuron in A $\beta \mathrm{O}$-injected $\mathrm{PV}-\mathrm{Cre}$ mice $(n=8$, orange). Mean phase (e) and mean length (f) of resultant vector. $\mathbf{g}-\mathbf{j}$ Same as $\mathbf{c - f}$ but for CA1 PC spike phases relative to gamma oscillations recorded in DMSO-injected mice ( $n=19$, black), A $\beta O$-injected mice $(n=13$, red), with blue light stimulation of ChR2-expressing SST interneuron in A $\beta O$-injected SST-Cre mice ( $n=6$, green), and with blue light stimulation of ChR2-expressing PV interneuron in A $\beta O$-injected PVCre mice ( $n=9$, orange). $n$ The number of CA1 PC units. WatsonWilliams multi-sample circular test $(\mathbf{e}, \mathbf{i}, * * * p<0.001$, N.S. $p>0.05)$ and one-way ANOVA followed by Tukey's post hoc test (f, j, $* * * p<0.001$, $* * p<0.01$, N.S. $p>0.05$ ). Data are mean \pm SEM with individual data values (dots) 
oscillations in A $\beta \mathrm{O}$-injected SST-Cre mice. Interestingly, 3-s long sustained blue light stimulation of ChR2-expressing SST interneurons in A $\beta O$-injected SST-Cre mice was able to restore the power of theta oscillations, while it had no effect on the power of impaired gamma oscillations, as shown in the band-pass filtered LFPs and the corresponding spectrograms (Fig. 11, m). Power spectral density (PSD) of unfiltered LFPs (Fig. 1n) confirmed that the effect of optogenetic activation of SST interneurons was indeed specific to theta oscillations, while delta, beta, and gamma oscillations remained unaffected. To further quantify the effect of SST interneuron activation on theta and gamma oscillations, we analyzed the peak powers and peak frequencies of theta and gamma oscillations from the PSD. We found that the peak power of theta oscillations that was significantly reduced in A $\beta O$-injected SSTCre mice was fully restored by the optogenetic activation of SST interneurons (Fig. 10) without affecting the peak frequency of theta oscillations (Fig. 1p), while there was no effect on peak powers nor peak frequencies of delta, beta, and gamma oscillations (Fig. 1q, r; Online resource Fig. 2). These results indicate that SST interneurons selectively restored the power of theta oscillations impaired in A $\beta O$-injected mice.

\section{Optogenetic activation of PV interneurons selectively restores the hippocampal gamma oscillations impaired in A $\beta O$-injected mice}

Next, we investigated the contribution of PV interneurons to the $\mathrm{A} \beta \mathrm{O}$-induced impairment of hippocampal theta and gamma oscillations in PV-Cre mice. Band-pass filtered LFPs and the corresponding spectrograms showed that the powers of both theta and gamma oscillations were also significantly reduced in $\mathrm{A} \beta \mathrm{O}$-injected $\mathrm{PV}-\mathrm{Cre}$ mice compared to those in DMSO-injected PV-Cre mice (Fig. 2a-d). 3-s long sustained blue light stimulation of ChR2-expressing PV interneurons in $\mathrm{A} \beta \mathrm{O}$-injected $\mathrm{PV}$-Cre mice had no effect on the impaired theta oscillations, while the power of gamma oscillations was restored as shown in the band-pass filtered LFPs and the corresponding spectrograms (Fig. 2e, f). The PSD of unfiltered LFPs (Fig. 2g) revealed that the effect of optogenetic activation of PV interneurons was specific to gamma oscillations as opposed to delta, theta and beta oscillations, which were all unaffected. The peak power of gamma oscillations that was significantly reduced in $\mathrm{A} \beta \mathrm{O}$-injected mice was fully restored by optogenetic activation of $\mathrm{PV}$ interneurons without affecting the peak frequency of gamma oscillations, while there was no effect on the peak powers and frequencies of delta, theta, and beta oscillations (Fig. 2h-k; Online resource Fig. 2).

Together, these results demonstrate that the $\mathrm{A} \beta \mathrm{O}$-induced decrease in the peak power of hippocampal theta and gamma oscillations can be selectively restored to control levels by optogenetic activation of SST and PV interneurons, respectively. In DMSO-injected control SST-Cre and PV-Cre mice, optogenetic activation of SST interneurons (Online resource Fig. 3) and PV interneurons (Online resource Fig. 4) also enhanced the peak power of theta and gamma oscillations, respectively, further supporting that distinct subtypes of interneurons are selectively involved in theta and gamma oscillations in both $\mathrm{AD}$ and the healthy brain.

\section{Optogenetic activation of SST and PV interneurons resynchronizes CA1 PC spike phases relative to theta and gamma oscillations, respectively, in ABO-injected mice}

CA1 PC spikes preferentially occur at specific phases of hippocampal network oscillations and this synchronization is thought to be critical for spatial navigation and memory functions (Dragoi and Buzsaki 2006; Maurer and McNaughton 2007; O'Keefe and Recce 1993; Skaggs et al. 1996). Therefore, we next investigated the effect of $A \beta O$ on CA1 PC spike synchrony with or without blue light stimulation of SST and PV interneurons. Recorded single units were divided into putative CA1 PCs and interneurons based on the spike waveforms (Fig. 3a), spike inter-spike intervals and autocorrelogram (see "Materials and methods"). Putative interneurons were further subdivided into putative SST and putative PV interneurons based on their increased firing rates in response to blue light stimulation in the peristimulus time histogram (PSTH, Fig. 3b). To quantify the strength of synchronization of CA1 PC spikes during theta oscillations, we analyzed the probability distribution of CA1 PC spike phases relative to the theta cycle in DMSO-injected mice and before/during blue light stimulation of SST and $\mathrm{PV}$ interneurons in $\mathrm{A} \beta \mathrm{O}-$ injected mice. In DMSO-injected mice, CA1 PCs spike phases were strongly locked before the trough of the theta cycle (Fig. 3c-f, black), consistent with previous in vivo recordings in anesthesia states (Klausberger et al. 2003; Somogyi et al. 2014; Klausberger and Somogyi 2008). Theta spike phases of CA1 PC in A $\beta O$-injected mice occurred at a significantly earlier phase before the trough of theta oscillations (Fig. 3c-e, red) with reduced mean vector length of spike phase compared to those in DMSO-injected mice (Fig. 3c, d, f, red). However, blue light stimulation of SST interneurons in A $\beta O$-injected SST-Cre mice (Fig. 3c-f, green), but not $\mathrm{PV}$ interneuron in $\mathrm{A} \beta \mathrm{O}$-injected $\mathrm{PV}-\mathrm{Cre}$ mice (Fig. 3c-f, orange), restored the mean spike phase (Fig. 3e) and the mean vector length of spike phase similar to those in the DMSO-injected mice (Fig. 3f).

The same CA1 PC spike phase analyses were repeated relative to gamma oscillations. In DMSO-injected mice, CA1 PCs spiked preferentially at the trough of the gamma cycle (Fig. 3g-j, black), consistent with previous in vivo recordings 


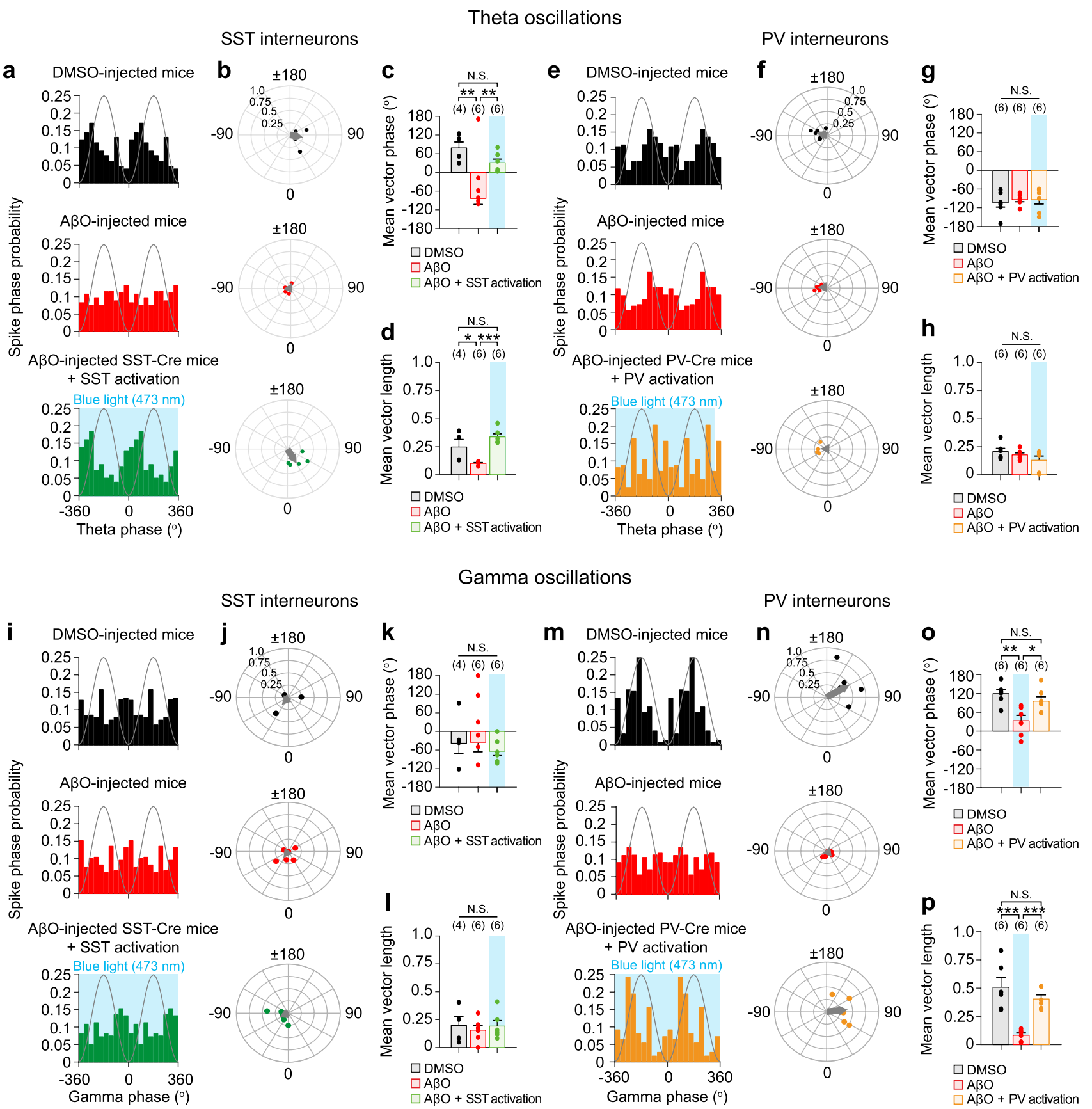

in anesthesia states (Tukker et al. 2007, 2013; Lasztoczi et al. 2011). In A $\beta O$-injected mice, gamma spike phases of CA1 PCs occurred at a significantly later phase after the trough of the gamma oscillations with lower mean vector length of spike phase compared to those in DMSO-injected mice (Fig. 3g-j, red). However, blue light stimulation of PV interneurons in A $\beta O$-injected PV-Cre mice (Fig. 3g-j, orange), but not SST interneurons in A $\beta O$-injected SST-Cre mice (Fig. 3g-j, green), restored the mean spike phase (Fig. 3i) and vector length of spike phase (Fig. 3j) similar to those in the DMSO-injected mice. Together, these results show that optogenetic activation of SST and PV interneurons selectively resynchronizes and increases the synchrony strength of the CA1 PC spikes relative to theta and gamma oscillations, respectively.

\section{Optogenetic activation of SST and PV interneurons resynchronizes SST and PV spike phases relative to theta and gamma oscillations, respectively, in $A \beta O$-injected mice in vivo}

The generation of robust theta and gamma oscillations is thought to be helped by synchronized spiking of SST and 
४Fig. 4 Optogenetic activation of SST and PV interneurons resynchronizes SST and PV interneuron spike phases relative to theta and gamma oscillations, respectively, in $\mathrm{A} \beta \mathrm{O}$-injected mice in vivo. The probability distribution of SST interneuron spike phases relative to theta oscillations (a) and polar plot of resultant vector phase/vector length (b, filled circles) and the mean resultant vectors (b, gray arrow) analyzed from theta phase distribution of individual SST interneuron in DMSO-injected SST-Cre mice ( $n=4$, black), A $\beta O-$ injected SST-Cre mice $(n=6$, red), and with blue light $(473 \mathrm{~nm})$ stimulation (blue shade) of ChR2-expressing SST interneuron in A $\beta O$-injected SST-Cre mice ( $n=6$, green). Mean phase (c) and mean length (d) of resultant vector. $\mathbf{e}-\mathbf{h}$ Same as in a-d but for PV interneuron spike phases relative to theta oscillations in DMSOinjected PV-Cre mice ( $n=6$, black), A $\beta O$-injected PV-Cre mice ( $n=6$, red), and with blue light stimulation of ChR2-expressing $\mathrm{PV}$ interneuron in $\mathrm{A} \beta \mathrm{O}$-injected $\mathrm{PV}-\mathrm{Cre}$ mice $(n=6$, orange). The probability distribution of SST interneuron spike phases relative to gamma oscillations (i) and polar plot of resultant vector phase/vector length ( $\mathbf{j}$, filled circles) and the mean resultant vectors ( $\mathbf{j}$, gray arrow) analyzed from gamma phase distribution of individual SST interneuron in DMSO-injected SST-Cre mice ( $n=4$, black), A $\beta O-$ injected SST-Cre mice $(n=6$, red), and with blue light stimulation of ChR2-expressing SST interneuron in A $\beta O$-injected SST-Cre mice ( $n=6$, green). Mean phase (k) and mean length (l) of resultant vector. $\mathbf{m}-\mathbf{p}$ Same as in $\mathbf{i}-\mathbf{l}$ but for PV interneuron spike phases relative to gamma oscillations in DMSO-injected PV-Cre mice ( $n=6$, black), A $\beta O$-injected PV-Cre mice ( $n=6$, red), and with blue light stimulation of ChR2-expressing PV interneuron in A $\beta O$-injected PV-Cre mice ( $n=6$, orange). $n$ The number of SST or PV interneuron units. Watson-Williams multi-sample circular test $(\mathbf{c}, \mathbf{g}, \mathbf{k}, \mathbf{o}, * * p<0.01$, ${ }^{*} p<0.05$, N.S. $\left.p>0.05\right)$ and one-way ANOVA followed by Tukey's post hoc test (d, h, l, p, ${ }^{* * *} p<0.001,{ }^{*} p<0.05$, N.S. $\left.p>0.05\right)$. Data are mean \pm SEM with individual data values (dots)

PV interneurons at specific phases relative to ongoing oscillations (Amilhon et al. 2015; Gulyas et al. 2010; Huh et al. 2016; Mann et al. 2005; Mikulovic et al. 2018; Wang and Buzsaki 1996), which in turn synchronizes the CA1 PC activity (Mann and Paulsen 2007; Cobb et al. 1995; Zemankovics et al. 2013). Thus, we investigated the effect of A $\beta O$ on spike phases of SST and PV interneurons relative to theta and gamma oscillations. First, we analyzed the probability distribution of SST and PV interneurons' spike phases relative to the theta cycles in DMSO-injected mice and before/ during blue light stimulation of SST and PV interneurons in $\mathrm{A} \beta \mathrm{O}$-injected mice in vivo. In DMSO-injected mice, SST interneuron preferentially spiked near the trough of the theta cycle (Fig. 4a-d, black), while PV interneuron preferentially spiked at the descending phase of the theta cycle (Fig. 4e-h, black), consistent with previous in vivo recordings in anesthetized states (Klausberger et al. 2003, 2004, 2005; Somogyi et al. 2014; Klausberger and Somogyi 2008). Interestingly, in A $\beta \mathrm{O}$-injected mice, only SST interneuron spike phases were desynchronized relative to theta cycles showing advanced mean spike phase and reduced vector length of the spike phase (Fig. 4a-d, red), while those of PV interneurons were unaffected (Fig. 4e-h, red). Furthermore, blue light stimulation of SST interneurons in A $\beta O$-injected SST-Cre mice (Fig. 4a-d, green), but not PV interneurons in $\mathrm{A} \beta \mathrm{O}$-injected PV-Cre mice (Fig. $4 \mathrm{e}-\mathrm{h}$, orange), fully restored the mean spike phase (Fig. 4c, g) and vector length of the spike phase similar to those in the DMSO-injected mice (Fig. 4d, h).

We repeated the same spike phase analyses of SST and PV interneurons relative to gamma oscillations. In DMSOinjected mice, SST interneuron spiked near the trough of the gamma cycle (Fig. 4i-l, black), while PV interneuron preferentially spiked before the peak of the gamma cycle (Fig. $4 \mathrm{~m}-\mathrm{p}$, black), consistent with previous in vivo recordings in anesthetized states (Somogyi et al. 2014; Tukker et al. 2007, 2013). In A $\beta O$-injected mice, the mean spike phase and the mean vector length of the spike phase of SST interneurons relative to gamma cycle were unaffected (Fig. 4i-1, red), while only those of PV interneurons were altered (Fig. 4m-p, red). Blue light stimulation of ChR2expressing SST interneurons in A $\beta O$-injected SST-Cre mice had no significant effect on the mean spike phase and the mean vector length of the spike phase (Fig. $4 \mathrm{i}-1$, green). However, blue light stimulation of ChR2-expressing PV interneurons in $\mathrm{A} \beta \mathrm{O}$-injected $\mathrm{PV}-\mathrm{Cre}$ mice fully restored the mean spike phase and vector length of the spike phase similar to the effects observed in DMSO-injected mice (Fig. $4 \mathrm{~m}-\mathrm{p}$, orange). These results revealed that $\mathrm{A} \beta \mathrm{O}$ selectively desynchronized SST interneuron spikes relative to theta oscillations and PV interneuron spikes relative to gamma oscillations, which could be restored by optogenetic activation of SST and PV interneurons, respectively.

\section{Frequency-specific enhancement of sIPSC rates by optogenetic activation of SST and PV interneurons in $\mathrm{A} \beta \mathrm{O}$-injected mice ex vivo}

Our results so far beg the question how sustained optogenetic activation of SST and PV interneurons can selectively resynchronize spike phases of CA1 PC (Fig. 3) and SST/ $\mathrm{PV}$ interneurons (Fig. 4) relative to theta and gamma oscillations in a frequency-specific manner, thereby restoring impaired theta and gamma oscillations (Figs. 1,2). Since precisely-timed inhibition provided by SST and PV interneurons is critical in theta and gamma oscillogenesis (Gulyas et al. 2010; Huh et al. 2016; Mann et al. 2005; Veit et al. 2017), we hypothesized that optogenetic activation of SST and PV interneurons may provide inhibition to CA1 PC in a frequency-selective manner. To test this, we obtained ex vivo whole-cell voltage-clamp recordings from CA1 $\mathrm{PC}$ in acute hippocampal slices of A $\beta \mathrm{O}$-injected SST-Cre mice or PV-Cre mice and recorded sIPSCs during 3 s-long sustained blue light stimulation of ChR2-expressing SST interneurons (Fig. 5a, b) or ChR2-expressing PV interneurons (Fig. 5c, d). Analysis of the sIPSC rate as the total number of sIPSCs during the blue light stimulation revealed that blue light stimulation of SST interneurons generated 


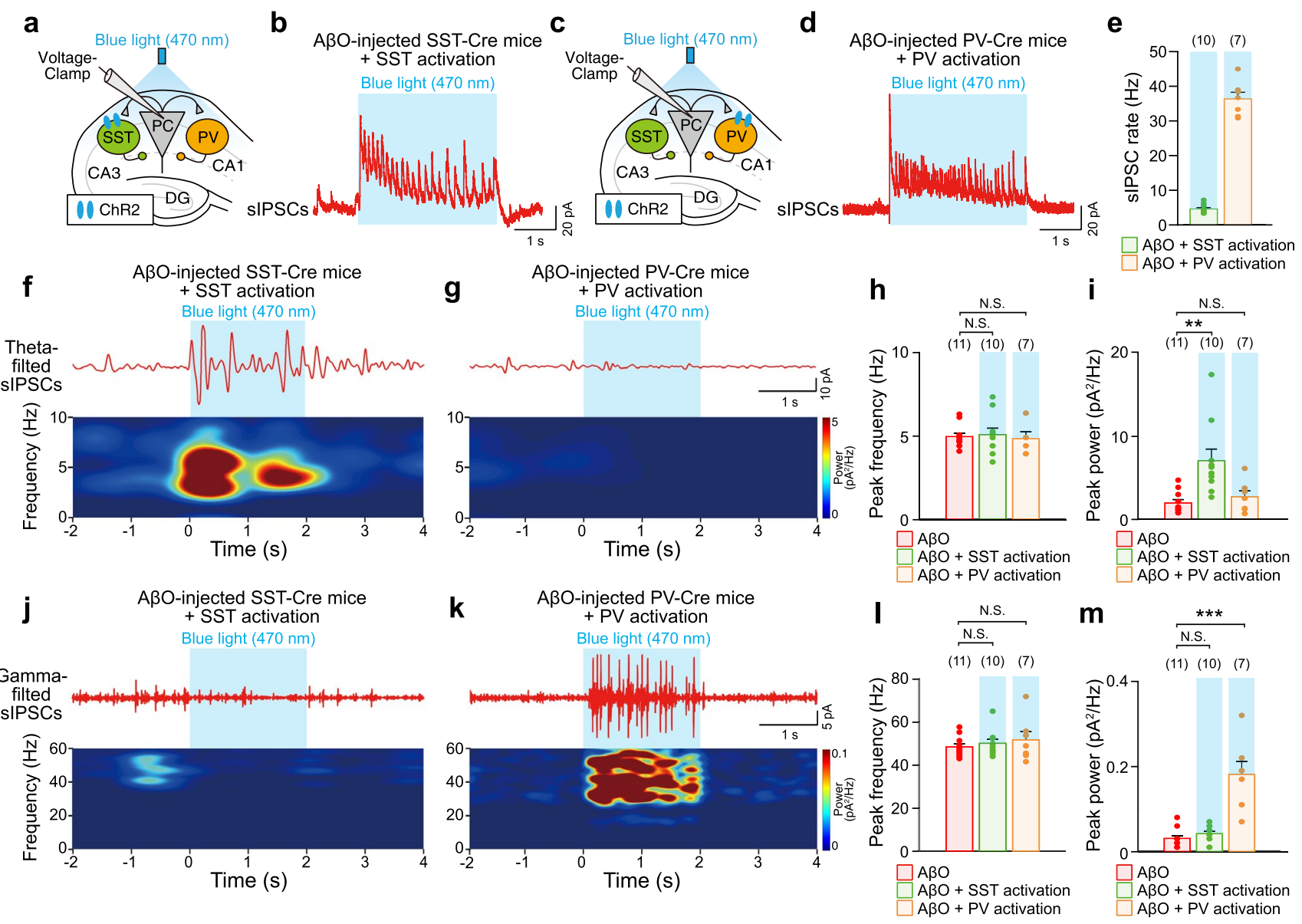

Fig. 5 Sustained optogenetic activation of SST and PV interneurons in A $\beta O$-injected mice activates sIPSCs selectively at theta and gamma frequencies. a Schematic illustrating whole-cell voltageclamp recordings of sIPSCs from CA1 $\mathrm{PC}$ in ex vivo hippocampal slices from $\mathrm{A} \beta \mathrm{O}$-injected SST-Cre mice during sustained blue light $(470 \mathrm{~nm})$ stimulation of ChR2-expressing SST interneurons. b Representative trace of sIPSCs recorded in CA1 PC during blue light stimulation (blue shade) of ChR2-expressing SST interneurons. c, d Same as a, b but sIPSCs recorded in CA1 PC during blue light stimulation of ChR2-expressing PV interneurons in A $\beta O$-injected PV-Cre mice. e Mean rates of sIPSCs recorded during blue light stimulation of ChR2-expressing SST interneurons in A $\beta O$-injected SST-Cre mice ( $n=10$, green) and during blue light stimulation of ChR2-expressing $\mathrm{PV}$ interneurons in A $\beta \mathrm{O}$-injected PV-Cre mice ( $n=7$, orange). Representative traces of band-pass filtered sIPSCs at theta frequency (top)

sIPSCs in the theta frequency-range (Fig. 5e, green), while blue light stimulation of PV interneurons generated sIPSCs in the gamma frequency-range (Fig. 5e, orange). Analyses of band-pass filtered sIPSCs at theta frequency and the corresponding spectrograms (Fig. 5f, g) revealed that while the peak frequencies of sIPSCs were unaltered (Fig. 5h), the peak power of sIPSCs at theta frequency was increased only by optogenetic activation of ChR2-expressing SST interneurons but not by ChR2-expressing PV interneurons (Fig. 5i). In contrast, band-pass filtered sIPSCs at gamma frequency (Fig. 5j, k) revealed that while the peak frequency and the corresponding power spectrograms (bottom) during sustained blue light stimulation of ChR2-expressing SST interneurons (f) and ChR2-expressing PV interneurons (g) in ex vivo hippocampal slices from A $\beta O$-injected SST-Cre and PV-cre mice, respectively. Mean peak frequency (h) and mean peak power (i) of band-pass filtered sIPSCs at theta frequency during blue light stimulation of ChR2expressing SST interneurons in A $\beta O$-injected SST-Cre mice mice ( $n=10$, green) and during blue light stimulation of ChR2-expressing $\mathrm{PV}$ interneurons in $\mathrm{A} \beta \mathrm{O}$-injected PV-Cre mice mice ( $n=7$, orange). $\mathbf{j}-\mathbf{m}$ Same as $\mathbf{f}-\mathbf{i}$ but for band-pass filtered sIPSCs at gamma frequency. $n$ The number of cells from which sIPSCs were recorded. One-way ANOVA followed by Tukey's post hoc test $(\mathbf{h}, \mathbf{i}, \mathbf{l}, \mathbf{m}$, $* * * p<0.001, * * p<0.01$, N.S. $p>0.05)$. Data are mean \pm SEM with individual data values (dots)

of sIPSCs was unchanged (Fig. 51), the peak power of sIPSCs at gamma frequency was significantly increased only by optogenetic activation of ChR2-expressing PV interneurons, but not by ChR2-expressing SST interneurons (Fig. 5m). Similar enhancements of the peak power of sIPSCs at theta and gamma frequencies by optogenetic activation of ChR2-expressing SST and PV interneurons, respectively, were observed in ex vivo brain slices from DMSO-injected SST-Cre/PV-Cre mice (Online resource Fig. 5). These results indicate that optogenetic activation of SST and $\mathrm{PV}$ interneurons increases sIPSC rates onto CA1 PC in a 
frequency-specific manner, contributing to the enhancement of the peak power of theta and gamma oscillations, respectively, in both, models of $\mathrm{AD}$ and the healthy brain.

\section{$A \beta O$ induces frequency-specific presynaptic dysfunctions of SST and PV interneurons' input to CA1 PC}

Then, what are the synaptic mechanisms underlying frequency-selective impairments of theta and gamma oscillations induced by $\mathrm{A} \beta \mathrm{O}$ ? Desynchronized SST and PV interneurons' firing relative to oscillations in $\mathrm{A} \beta \mathrm{O}$-injected mice (Fig. 4) suggests that $A \beta O$ may have decreased the strength of SST/PV interneuron-evoked inhibitory input into CA1 PC. Moreover, enhancement of sIPSC powers at theta and gamma frequencies by optogenetic activation of SST and PV interneurons ex vivo, respectively (Fig. 5), indicates that the optogenetic activation might restore the amplitude of sIPSCs impaired by $\mathrm{A} \beta \mathrm{O}$. Thus, we hypothesized that $\mathrm{A} \beta \mathrm{O}$ disrupts SST and PV interneuron-evoked synaptic inputs to CA1 PC leading to a desynchronization of CA1 PC spikes. To test this hypothesis, we conducted ex vivo whole-cell voltage-clamp recordings from CA1 PC and recorded IPSCs evoked by a single or repetitive brief pulses of blue light stimulation of ChR2-expressing SST (SST-evoked IPSCs, Fig. 6a, b) and PV interneurons (PV-evoked IPSCs, Fig. 6c, d) in hippocampal slices from DMSO-injected and A $\beta O$ injected SST-Cre/PV-Cre mice. We first analyzed the $S-R$ curve of SST-evoked IPSCs (Fig. 6b) and PV-evoked IPSCs (Fig. 6d) in response to a single pulse of different blue light intensities $[5,10,25,50,75$, and $100 \%$ of maximal light power $(15 \mathrm{~mW})]$. In ex vivo hippocampal slices from A $\beta O-$ injected mice, the amplitudes of both SST-evoked IPSCs and PV-evoked IPSCs were significantly increased at each given light intensity, compared to those in DMSO-injected mice (Fig. 6b, d, right), which indicates that $\mathrm{A} \beta \mathrm{O}$ altered both SST-to-PC and PV-to-PC synapses to enhance the initial GABA release probability in $\mathrm{A} \beta \mathrm{O}$-injected mice. Interestingly, the $S-R$ curves of both SST- and PV-evoked IPSCs in the $\mathrm{A} \beta \mathrm{O}$-injected mice reached significantly higher plateaus than in the DMSO-injected mice at high light intensities (Fig. 6b, d, right), which argues against the possibility that the difference in IPSC sizes is due to a change in optogenetic stimulation-induced increase in interneuron excitability, as we would then expect the $S-R$ curves to eventually reach the same plateau. Since SST and PV interneurons' inhibitory inputs to CA1 PC were tuned at theta and gamma frequencies, respectively (Fig. 5), we further investigated whether A $\beta O$-induced synaptic dysfunctions at SST-to-PC and PV-to-PC synapses had frequency-dependence. To test this, we delivered ten pulses of blue light at $5 \mathrm{~Hz}$ and $40 \mathrm{~Hz}$ in ex vivo slices from DMSO-injected and $\mathrm{A} \beta \mathrm{O}$-injected mice to record SST-evoked IPSCs (Fig. 6e, i, black traces) and PV-evoked IPSCs (Fig. 6g, k, black traces) and analyzed PPR and short-term plasticity (Fig. 6f, h, j, l). In doing so, we used half-maximal blue light stimulation intensity based on the $S-R$ curve (Fig. 6 b, d) to ensure that the light stimulation intensity does not affect the neurotransmitter release probability, a method widely used in investigating synaptic properties (Ciani et al. 2015; He et al. 2019; Rice et al. 2019; Abramov et al. 2009; Phillips et al. 2008). When we analyzed the first two-consecutive IPSCs evoked by SST or PV interneurons, we found that paired-pulse depression of SST-evoked IPSCs, as observed in slices from DMSOinjected mice, was further depressed only for $5 \mathrm{~Hz}$ stimulation (Fig. 6f, j, left), while paired-pulse depression of PV-evoked IPSCs was further depressed only for $40 \mathrm{~Hz}$ stimulation (Fig. 6h, 1, left). Similarly, when all ten pulses were analyzed for short-term plasticity, SST-evoked IPSCs and PV-evoked IPSCs at both 5 and $40 \mathrm{~Hz}$ showed robust short-term depression (Fig. 6f, h, j, l, right, black) of IPSCs in slices from DMSO-injected slices, while in hippocampal slices from $\mathrm{A} \beta \mathrm{O}$-injected mice, short-term depression was further depressed only at $5 \mathrm{~Hz}$ for SST-evoked IPSCs (Fig. 6f, j, right, red) and only at $40 \mathrm{~Hz}$ for PV-evoked IPSCs (Fig. 6h, l, right, red). These results indicate that $\mathrm{A} \beta \mathrm{O}$ causes presynaptic dysfunctions at SST-to-PC and PV-to-PC synapses by increasing the initial GABA release probability to depress SST-evoked and PV-evoked IPSCs selectively at theta and gamma frequencies, respectively. Finally, we asked whether A $\beta \mathrm{O}$-induced dysfunctions of SST and PV interneurons' inhibitory inputs to $\mathrm{CA} 1 \mathrm{PC}$ in $\mathrm{A} \beta \mathrm{O}$-injected mice could be restored by the sustained optogenetic activation of SST and PV interneurons. For this, we analyzed the mean amplitude of sIPSCs recorded in ex vivo slices from DMSO-injected mice (Fig. 6m, top), A $\beta O$-injected mice (Fig. $6 \mathrm{~m}$, bottom), and $\mathrm{A} \beta \mathrm{O}$-injected mice during sustained blue light stimulation of ChR2-expressing SST interneuron (Fig. 6n, top) and ChR2-expressing PV interneuron (Fig. 6n, bottom). Compared to the sIPSCs recorded in ex vivo slices from DMSO-injected mice, the mean amplitudes of sIPCSs were significantly reduced in ex vivo slices from $\mathrm{A} \beta \mathrm{O}$ injected mice (Fig. 6o, p). Such A $\beta O$-induced reduction of sIPSC amplitude was fully restored by optical stimulation of SST and PV interneurons (Fig. 6o, p). Taken together, these results demonstrate for the first time that $\mathrm{A} \beta \mathrm{O}$ causes presynaptic dysfunction at SST-to-PC and PV-to-PC synapses by increasing the initial synaptic release probabilities, which leads to a frequency-specific and cell type-specific depression in SST-evoked IPSCs and PV-evoked IPSCs. Such A $\beta O$-induced depression of inhibitory input to CA1 PC may underlie the desynchronization of CA1 PC spikes, leading to a reduction in theta and gamma oscillation powers in vivo in $\mathrm{A} \beta \mathrm{O}$-injected mice. 


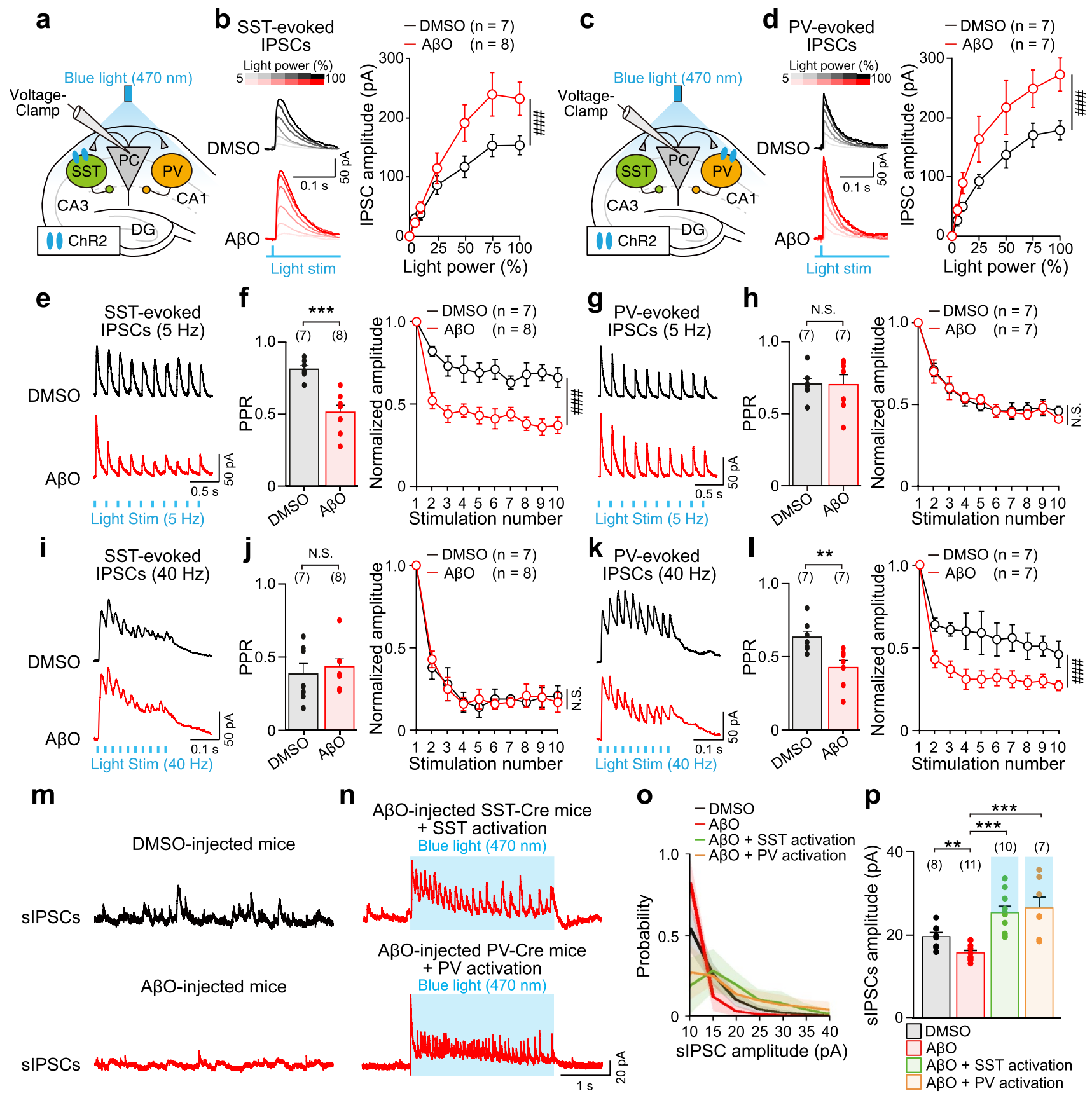

\section{Discussion}

In this study, we injected $\mathrm{A} \beta \mathrm{O}$ into the hippocampus to create $\mathrm{A} \beta \mathrm{O}$ pathology in vivo, a method adopted in many studies investigating the impact of $\mathrm{A} \beta \mathrm{O}$ on physiological and cognitive functions (Villette et al. 2010; Meyer-Luehmann et al. 2006; Stephan et al. 2001, 2003; Walsh et al. 2002). The major advantage of using the $\mathrm{A} \beta \mathrm{O}$-injection mouse model of AD was that we were able to perform optogenetic activation of SST and PV interneurons in cre-transgenic animals. Using this AD mouse model, we showed, for the first time, that sustained optogenetic activation of SST and
PV interneurons could selectively restore the power of hippocampal theta and gamma oscillations impaired by $\mathrm{A} \beta \mathrm{O}$ pathology in vivo, respectively, (Figs. 1,2) without affecting other frequencies such as delta and beta oscillations (Online resource Fig. 2), and resynchronize the CA1 PC spike phases relative to both theta and gamma oscillations to the level observed in the control mice (Fig. 3). Further analyses revealed that SST and PV interneurons' spike phases desynchronized specifically relative to theta and gamma oscillation cycles, respectively (Fig. 4), which were also resynchronized by the optogenetic manipulations. Ex vivo whole-cell patch-clamp recordings of sIPSCs from CA1 PC 
4Fig. 6 A $\beta O$ induces presynaptic dysfunctions of SST and PV interneurons' input to CA1 PC. a Schematic illustrating whole-cell voltage-clamp recordings of evoked-IPSCs from CA1 PC in response to blue light $(470 \mathrm{~nm})$ stimulation (blue shade) of ChR2-expressing SST interneurons in ex vivo hippocampal slices from DMSO-injected and A $\beta O$-injected SST-Cre mice. b Representative traces of SST interneuron-evoked IPSCs (SST-evoked IPSCs, left) recorded in CA1 $\mathrm{PC}$ and stimulus-response $(S-R)$ curve (right) in response to different light stimulation intensities $(5,10,25,50,75$, and $100 \%$ of maximum power $(15 \mathrm{~mW})$ ) in hippocampal slices from DMSO-injected mice $(n=7$, black), A $\beta O$-injected mice $(n=8$, red). c, d Same as a, b but for PV interneuron-evoked IPSCs (PV-evoked IPSCs) recorded in CA1 PC (DMSO: $n=7, \mathrm{~A} \beta \mathrm{O}: n=7$ ). Representative traces of SST-evoked IPSCs (e), paired-pulse ratio (PPR) (f, left), and SSTevoked-IPSCs normalized to the first evoked-IPSC showing shortterm depression (f, right) in response to a train of ten pulses of blue light stimulation at $5 \mathrm{~Hz}$ in ex vivo hippocampal slices from DMSOinjected mice ( $n=7$, black) and $\mathrm{A} \beta \mathrm{O}$-injected mice $(n=8$, red). $\mathbf{g}, \mathbf{h}$ Same as e-f but with PV-evoked IPSCs recorded in CA1 PC (DMSO: $n=7$, A $\beta O: n=7)$. $\mathbf{i}-\mathbf{l}$ Same as $\mathbf{e}-\mathbf{h}$ but in response to a train of ten pulses of blue light stimulation at $40 \mathrm{~Hz}$. Representative traces of sIPSCs recorded in CA1 PC in the hippocampal slices from DMSOinjected mice (m, top, black), A $\beta \mathrm{O}$-injected mice (m, bottom, red), $\mathrm{A} \beta \mathrm{O}$-injected mice during sustained blue light stimulation of ChR2expressing SST interneurons (n, top, red), and ChR2-expressing PV interneurons (n, bottom, red). Probability distribution of sIPSC amplitudes (o) and mean amplitudes of sIPSCs (p) in each condition (DMSO: $n=8, \mathrm{~A} \beta \mathrm{O}: n=11, \mathrm{~A} \beta \mathrm{O}+\mathrm{SST}$ activation: $n=10, \mathrm{~A} \beta \mathrm{O}+\mathrm{PV}$ activation: $n=7)$. $n$ The number of cells from which evoked IPSCs or sIPSCs were recorded. Two-way ANOVA followed by Tukey's post hoc test (b, d, f, right, h, right, j, right, l, right, ${ }^{\# \#} p<0.001$, N.S. $p>0.05$ ), unpaired Student's $t$ test (f, left, h, left, $\mathbf{j}$, left, l, left, $* * * p<0.001, * * p<0.01$, N.S. $p>0.05$ ), and one-way ANOVA followed by Tukey's post hoc test $\left(\mathbf{p},{ }^{* * *} p<0.001, * * p<0.01\right)$. Data are mean \pm SEM with individual data values (dots)

in hippocampal slices prepared from $\mathrm{A} \beta \mathrm{O}$-injected mice revealed that optogenetic activation of SST and PV interneurons selectively enhanced SIPSC rates at theta and gamma frequencies, respectively (Fig. 5), providing a mechanisms for the observed restoration of theta and gamma oscillations in vivo. Moreover, analysis of the $S-R$ curve, PPR, and short-term plasticity of SST-evoked and PV-evoked IPSCs showed that $\mathrm{A} \beta \mathrm{O}$ induced presynaptic dysfunctions at SST-to-PC and PV-to-PC synapses by depressing SST and $\mathrm{PV}$ interneurons' input to $\mathrm{CA} 1 \mathrm{PC}$ in a frequency-specific manner, accounting for the reduction in the power of theta and gamma oscillations, respectively. Taken together, our results provide mechanistic insight into the inhibitory neural circuit dysfunctions underlying $\mathrm{A} \beta \mathrm{O}$-induced theta and gamma oscillation impairments in vivo and identify SST and PV interneurons as targets for restoring hippocampal network oscillation impairments in early AD.

Hippocampal gamma and theta oscillations, which are important in memory function, have been reported to be impaired in mouse models of AD (Wang et al. 2002; Scott et al. 2012; Villette et al. 2010; Iaccarino et al. 2016; Driver et al. 2007; Palop and Mucke 2016; Goutagny et al. 2013; Ittner et al. 2014; Mondragon-Rodriguez et al. 2018). Thus, many previous studies investigated ways in which hippocampal oscillations could be restored. PV interneurons have long been implicated in gamma oscillations (Gulyas et al. 2010; Mann et al. 2005), and consequently their activity has been manipulated to restore gamma oscillations in mouse models of AD through methods such as optogenetic activation of PV interneurons (Iaccarino et al. 2016), implantation of PV-like fast-spiking interneurons (Martinez-Losa et al. 2018; Tong et al. 2014) and even ablation of certain genes in PV interneurons (Verret et al. 2012; Zhang et al. 2017), which are in line with our results. However, no study has yet been able to suggest methods to restore theta oscillation impairments observed in mouse models of AD. As for SST interneurons, their roles on hippocampal oscillogenesis appear more varied (Amilhon et al. 2015; Huh et al. 2016; Mikulovic et al. 2018). Some studies report that the activity of SST interneurons is synchronized with gamma oscillations in vivo (Tukker et al. 2007) and optogenetic activation of SST interneurons can modulate gamma oscillations in vivo and ex vivo (Hakim et al. 2018; Veit et al. 2017). Recently, optogenetic activation of O-LM cells, a subset of SST interneurons, were shown to induce theta frequency oscillations in vivo in awake behaving animals (Mikulovic et al. 2018). Consistent with these results, our in vivo (Online resource Fig. 3) and ex vivo experiments (Online resource Fig. 5) demonstrate that optogenetic activation of SST interneurons enhances theta oscillations in healthy brains. To our knowledge, this is the first demonstration that optogenetic activation of SST interneurons selectively restores theta oscillations and resynchronizes CA1 PC spikes relative to theta oscillations in a mouse model of $\mathrm{AD}$ in vivo by selectively restoring the dysfunctional SST interneuronal input to CA1 PC.

Through spike phase analyses of CA1 PC relative to theta and gamma frequency oscillations, we were able to identify that their spike phases were desynchronized in $\mathrm{A} \beta \mathrm{O}$-injected mice (Fig. 3), which is consistent with other studies (Kurudenkandy et al. 2014; Mably et al. 2017). However, we also found that, in $\mathrm{A} \beta \mathrm{O}$-injected mice, SST and PV interneurons' synchrony strengths were selectively reduced relative to theta and gamma oscillations, respectively (Fig. 4). These results led us to show that $\mathrm{A} \beta \mathrm{O}$ causes interneuron subtypespecific and frequency-specific impairments of inhibitory input to CA1 PC, as further confirmed through experiments ex vivo (Figs. 5, 6).

We found that sustained optogenetic activation of SST and PV interneurons in A $\beta O$-injected mice increase sIPSC rates selectively at theta and gamma frequencies, respectively (Fig. 5). These results indicate that optogenetic activation of these interneurons restored neuronal output in a frequency-specific manner, which contributed to the restoration of theta and gamma oscillations in vivo in Figs. 1 and 2. In fact, such frequency-specific restoration of theta and gamma 
oscillations could be in part explained by additional excitation provided by optogenetic activation of SST/PV interneurons allowing for the activation of SST/PV interneuronal networks to a critical level for oscillations, which would otherwise show reduced activation due to the $\mathrm{A} \beta \mathrm{O}$-induced decrease in the excitation level in SST and PV interneurons (Hanson 2017; Schmid et al. 2016; Park et al. 2020). Indeed, optogenetic activation of SST and PV interneurons restored the sIPSC amplitudes to the level observed in DMSOinjected mice (Fig. 6) by increasing excitation to SST and PV interneurons. This led to increased spontaneous firing of SST or PV interneurons, similar to what has been reported in other studies (Song et al. 2013; Yi et al. 2014).

To better dissect the synaptic mechanisms underlying $\mathrm{A} \beta \mathrm{O}$-induced impairments of theta and gamma oscillations, we analyzed the $S-R$ curve, PPR, and short-term plasticity of SST/PV interneuron-evoked IPSCs in ex vivo slices and were able to show that $\mathrm{A} \beta \mathrm{O}$ enhances both paired-pulse depression and short-term depression of SST/PV interneuron-evoked IPSCs (Fig. 6). These results suggest that $\mathrm{A} \beta \mathrm{O}$ increases the initial synaptic release probability of SST and $\mathrm{PV}$ interneurons resulting in a depression of their synaptic weights to CA1 PC. This effect selectively occurs for SST interneurons at theta and PV interneurons at gamma frequencies, which may explain $\mathrm{A} \beta \mathrm{O}$-induced impairment of theta and gamma oscillations as well as desynchronization of PC, SST and PV interneurons' spike phases. However, we cannot rule out the possibility that these frequency-selective presynaptic dysfunctions of SST/PV interneurons inputs to CA1 PC might result from changes in the level of activation of SST/PV interneurons or in the resonant properties of the network by the repeated light pulses. In addition, since activation of SST interneurons has been shown to recruit PV interneurons (Cottam et al. 2013; Xu et al. 2013) or vice versa (Karnani et al. 2016; Walker et al. 2016), it is possible that optogenetic activation of SST/PV interneurons could have restored the amplitudes of sIPSCs by altering the number of co-active SST/PV interneurons. Thus, future experiments will require dual recordings of interneuron and PC pairs to ascertain the presynaptic dysfunctions we describe here.

Although our study dissects the contributions of SST and PV interneurons to theta and gamma oscillations in an ADmodel and healthy brains, one thing to note in interpreting our data is that all in vivo recordings were performed under anesthesia. While there are reports that the power of theta oscillations was reduced in transgenic mouse models of $\mathrm{AD}$ such as $3 x \operatorname{Tg}$ ex vivo (Mondragon-Rodriguez et al. 2018), CRND8 ex vivo (Goutagny et al. 2013), APP/PS1 in vivo (Wang et al. 2002; Scott et al. 2012), APP23 in vivo (Ittner et al. 2014), one study reported that theta oscillations during spatial navigation in awake behaving mice was unaffected in 5XFAD mice in vivo (Zhang et al. 2016). These differences may arise depending on the behavioral states and differences in the transgenic mouse lines of AD. Therefore, it will be important to investigate how theta oscillations are affected in the awake $\mathrm{A} \beta \mathrm{O}$-injected mice and the effectiveness of optogenetic activation of SST and PV interneurons thereon. Moreover, hypersynchrony and epileptic activities observed in transgenic AD mice models (Palop et al. 2007) was absent in the $\mathrm{A} \beta \mathrm{O}$-injected mice in our and other studies (Kalweit et al. 2015). Hence, long-term effects of $A \beta O$ may also cause different impairments on hippocampal neural circuits, which will require further investigation.

Overall, by combining optogenetic manipulations of SST and PV interneurons in a A $\beta O$-injection mouse model of $\mathrm{AD}$ in vivo and ex vivo, we dissected the neural circuit dysfunction underlying theta and gamma oscillation impairments caused by $\mathrm{A} \beta \mathrm{O}$ pathology and show that hippocampal theta and gamma oscillations can be selectively restored by optogenetic activation of SST and PV interneurons, respectively. These results provide experimental evidence for how SST and PV interneurons contribute to theta and gamma oscillogenesis in the hippocampus and suggest that they could serve as potential therapeutic targets for restoring hippocampal oscillations in early stages of AD.

Acknowledgements This work was supported by a Grant of the Korea Health Technology R\&D Project through the Korea Health Industry Development Institute (KHIDI), funded by the Ministry of Health \& Welfare, Republic of Korea (HI17C0212, HI19C0646) to J. K. K. P. was supported by the Global Ph.D. Fellowship Program through the National Research Foundation of Korea (NRF) funded by Ministry of Education (NRF-2016H1A2A1907615).

\section{Compliance with ethical standards}

Conflict of interest The authors declare that they have no conflict of interest.

Open Access This article is licensed under a Creative Commons Attribution 4.0 International License, which permits use, sharing, adaptation, distribution and reproduction in any medium or format, as long as you give appropriate credit to the original author(s) and the source, provide a link to the Creative Commons licence, and indicate if changes were made. The images or other third party material in this article are included in the article's Creative Commons licence, unless indicated otherwise in a credit line to the material. If material is not included in the article's Creative Commons licence and your intended use is not permitted by statutory regulation or exceeds the permitted use, you will need to obtain permission directly from the copyright holder. To view a copy of this licence, visit http://creativecommons.org/licenses/by/4.0/.

\section{References}

Abramov E, Dolev I, Fogel H, Ciccotosto GD, Ruff E, Slutsky I (2009) Amyloid-beta as a positive endogenous regulator of release probability at hippocampal synapses. Nat Neurosci 12(12):1567-1576. https://doi.org/10.1038/nn.2433 
Alberdi E, Sanchez-Gomez MV, Cavaliere F, Perez-Samartin A, Zugaza JL, Trullas R, Domercq M, Matute C (2010) Amyloid beta oligomers induce $\mathrm{Ca}^{2+}$ dysregulation and neuronal death through activation of ionotropic glutamate receptors. Cell Calcium 47(3):264-272. https://doi.org/10.1016/j.ceca.2009.12.010

Amilhon B, Huh CY, Manseau F, Ducharme G, Nichol H, Adamantidis A, Williams S (2015) Parvalbumin interneurons of hippocampus tune population activity at theta frequency. Neuron 86(5):12771289. https://doi.org/10.1016/j.neuron.2015.05.027

Berens PJJSS (2009) CircStat: a MATLAB toolbox for circular statistics. J Stat Softw 31(10):1-21

Bikbaev A, Manahan-Vaughan D (2008) Relationship of hippocampal theta and gamma oscillations to potentiation of synaptic transmission. Front Neurosci 2(1):56-63. https://doi. org/10.3389/neuro.01.010.2008

Brouillette J, Caillierez R, Zommer N, Alves-Pires C, Benilova I, Blum D, De Strooper B, Buee L (2012) Neurotoxicity and memory deficits induced by soluble low-molecular-weight amyloidbeta1-42 oligomers are revealed in vivo by using a novel animal model. J Neurosci 32(23):7852-7861. https://doi.org/10.1523/ JNEUROSCI.5901-11.2012

Buzsaki G (2002) Theta oscillations in the hippocampus. Neuron 33(3):325-340

Chapman PF, White GL, Jones MW, Cooper-Blacketer D, Marshall VJ, Irizarry M, Younkin L, Good MA, Bliss TV, Hyman BT, Younkin SG, Hsiao KK (1999) Impaired synaptic plasticity and learning in aged amyloid precursor protein transgenic mice. Nat Neurosci 2(3):271-276. https://doi.org/10.1038/6374

Chen L, Saito T, Saido TC, Mody I (2018) Novel quantitative analyses of spontaneous synaptic events in cortical pyramidal cells reveal subtle parvalbumin-expressing interneuron dysfunction in a knock-in mouse model of Alzheimer's disease. eNeuro. doi: 10.1523/ENEURO.0059-18.2018.

Ciani L, Marzo A, Boyle K, Stamatakou E, Lopes DM, Anane D, McLeod F, Rosso SB, Gibb A, Salinas PC (2015) Wnt signalling tunes neurotransmitter release by directly targeting synaptotagmin-1. Nat Commun 6:8302. https://doi.org/10.1038/ ncomms9302

Cobb SR, Buhl EH, Halasy K, Paulsen O, Somogyi P (1995) Synchronization of neuronal activity in hippocampus by individual GABAergic interneurons. Nature 378(6552):75-78. https://doi. org/10.1038/378075a0

Cottam JC, Smith SL, Hausser M (2013) Target-specific effects of somatostatin-expressing interneurons on neocortical visual processing. J Neurosci 33(50):19567-19578. https://doi. org/10.1523/JNEUROSCI.2624-13.2013

De Felice FG, Velasco PT, Lambert MP, Viola K, Fernandez SJ, Ferreira ST, Klein WL (2007) Abeta oligomers induce neuronal oxidative stress through an $\mathrm{N}$-methyl-D-aspartate receptordependent mechanism that is blocked by the Alzheimer drug memantine. J Biol Chem 282(15):11590-11601. https://doi. org/10.1074/jbc.M607483200

Decker H, Lo KY, Unger SM, Ferreira ST, Silverman MA (2010) Amyloid-beta peptide oligomers disrupt axonal transport through an NMDA receptor-dependent mechanism that is mediated by glycogen synthase kinase 3beta in primary cultured hippocampal neurons. J Neurosci 30(27):9166-9171. https://doi. org/10.1523/JNEUROSCI.1074-10.2010

Dragoi G, Buzsaki G (2006) Temporal encoding of place sequences by hippocampal cell assemblies. Neuron 50(1):145-157. https ://doi.org/10.1016/j.neuron.2006.02.023

Driver JE, Racca C, Cunningham MO, Towers SK, Davies CH, Whittington MA, LeBeau FE (2007) Impairment of hippocampal gamma-frequency oscillations in vitro in mice overexpressing human amyloid precursor protein (APP).
Eur J Neurosci 26(5):1280-1288. https://doi.org/10.111 $1 / \mathrm{j} .1460-9568.2007 .05705 . \mathrm{x}$

Goutagny R, Gu N, Cavanagh C, Jackson J, Chabot JG, Quirion R, Krantic S, Williams S (2013) Alterations in hippocampal network oscillations and theta-gamma coupling arise before Abeta overproduction in a mouse model of Alzheimer's disease. Eur J Neurosci 37(12):1896-1902. https://doi.org/10.1111/ejn.12233

Gulyas AI, Szabo GG, Ulbert I, Holderith N, Monyer H, Erdelyi F, Szabo G, Freund TF, Hajos N (2010) Parvalbumin-containing fast-spiking basket cells generate the field potential oscillations induced by cholinergic receptor activation in the hippocampus. $\mathrm{J}$ Neurosci 30(45):15134-15145. https://doi.org/10.1523/JNEUR OSCI.4104-10.2010

Hakim R, Shamardani K, Adesnik H (2018) A neural circuit for gamma-band coherence across the retinotopic map in mouse visual cortex. Elife. https://doi.org/10.7554/eLife.28569

Hanson JE (2017) Identifying faulty brain circuits. Elife. https://doi. org/10.7554/eLife.26942

Hardy J, Selkoe DJ (2002) The amyloid hypothesis of Alzheimer's disease: progress and problems on the road to therapeutics. Science 297(5580):353-356. https://doi.org/10.1126/science.1072994

He Y, Wei M, Wu Y, Qin H, Li W, Ma X, Cheng J, Ren J, Shen Y, Chen Z, Sun B, Huang FD, Shen Y, Zhou YD (2019) Amyloid beta oligomers suppress excitatory transmitter release via presynaptic depletion of phosphatidylinositol-4,5-bisphosphate. Nat Commun 10(1):1193. https://doi.org/10.1038/s41467-019-09114-z

Hill DN, Mehta SB, Kleinfeld D (2011) Quality metrics to accompany spike sorting of extracellular signals. J Neurosci 31(24):86998705. https://doi.org/10.1523/JNEUROSCI.0971-11.2011

Hsieh H, Boehm J, Sato C, Iwatsubo T, Tomita T, Sisodia S, Malinow R (2006) AMPAR removal underlies Abeta-induced synaptic depression and dendritic spine loss. Neuron 52(5):831-843. https ://doi.org/10.1016/j.neuron.2006.10.035

Huerta PT, Lisman JE (1993) Heightened synaptic plasticity of hippocampal CA1 neurons during a cholinergically induced rhythmic state. Nature 364(6439):723-725. https://doi.org/10.1038/36472 $3 \mathrm{a} 0$

Huh CY, Amilhon B, Ferguson KA, Manseau F, Torres-Platas SG, Peach JP, Scodras S, Mechawar N, Skinner FK, Williams S (2016) Excitatory inputs determine phase-locking strength and spike-timing of CA1 stratum oriens/alveus parvalbumin and somatostatin interneurons during intrinsically generated hippocampal theta rhythm. J Neurosci 36(25):6605-6622. https://doi.org/10.1523/ JNEUROSCI.3951-13.2016

Iaccarino HF, Singer AC, Martorell AJ, Rudenko A, Gao F, Gillingham TZ, Mathys H, Seo J, Kritskiy O, Abdurrob F, Adaikkan C, Canter RG, Rueda R, Brown EN, Boyden ES, Tsai LH (2016) Gamma frequency entrainment attenuates amyloid load and modifies microglia. Nature 540(7632):230-235. https://doi.org/10.1038/ nature20587

Ittner AA, Gladbach A, Bertz J, Suh LS, Ittner LM (2014) p38 MAP kinase-mediated NMDA receptor-dependent suppression of hippocampal hypersynchronicity in a mouse model of Alzheimer's disease. Acta Neuropathol Commun 2:149. https://doi. org/10.1186/s40478-014-0149-z

Kalweit AN, Yang H, Colitti-Klausnitzer J, Fulop L, Bozso Z, Penke B, Manahan-Vaughan D (2015) Acute intracerebral treatment with amyloid-beta (1-42) alters the profile of neuronal oscillations that accompany LTP induction and results in impaired LTP in freely behaving rats. Front Behav Neurosci 9:103. https://doi. org/10.3389/fnbeh.2015.00103

Kamenetz F, Tomita T, Hsieh H, Seabrook G, Borchelt D, Iwatsubo T, Sisodia S, Malinow R (2003) APP processing and synaptic function. Neuron 37(6):925-937

Karnani MM, Jackson J, Ayzenshtat I, Tucciarone J, Manoocheri K, Snider WG, Yuste R (2016) Cooperative subnetworks of 
molecularly similar interneurons in mouse neocortex. Neuron 90(1):86-100. https://doi.org/10.1016/j.neuron.2016.02.037

Khodagholy D, Gelinas JN, Buzsaki G (2017) Learning-enhanced coupling between ripple oscillations in association cortices and hippocampus. Science 358(6361):369-372. https://doi.org/10.1126/ science.aan6203

Kim HG, Moon M, Choi JG, Park G, Kim AJ, Hur J, Lee KT, Oh MS (2014) Donepezil inhibits the amyloid-beta oligomer-induced microglial activation in vitro and in vivo. Neurotoxicology 40:2332. https://doi.org/10.1016/j.neuro.2013.10.004

Klausberger T, Somogyi P (2008) Neuronal diversity and temporal dynamics: the unity of hippocampal circuit operations. Science 321(5885):53-57. https://doi.org/10.1126/science.1149381

Klausberger T, Magill PJ, Marton LF, Roberts JD, Cobden PM, Buzsaki G, Somogyi P (2003) Brain-state- and cell-type-specific firing of hippocampal interneurons in vivo. Nature 421(6925):844-848. https://doi.org/10.1038/nature01374

Klausberger T, Marton LF, Baude A, Roberts JD, Magill PJ, Somogyi P (2004) Spike timing of dendrite-targeting bistratified cells during hippocampal network oscillations in vivo. Nat Neurosci 7(1):41-47. https://doi.org/10.1038/nn1159

Klausberger T, Marton LF, O’Neill J, Huck JH, Dalezios Y, Fuentealba P, Suen WY, Papp E, Kaneko T, Watanabe M, Csicsvari J, Somogyi P (2005) Complementary roles of cholecystokinin- and parvalbumin-expressing GABAergic neurons in hippocampal network oscillations. J Neurosci 25(42):9782-9793. https://doi. org/10.1523/JNEUROSCI.3269-05.2005

Kurudenkandy FR, Zilberter M, Biverstal H, Presto J, Honcharenko D, Stromberg R, Johansson J, Winblad B, Fisahn A (2014) Amyloid-beta-induced action potential desynchronization and degradation of hippocampal gamma oscillations is prevented by interference with peptide conformation change and aggregation. J Neurosci 34(34):11416-11425. https://doi.org/10.1523/JNEUR OSCI.1195-14.2014

Lacor PN, Buniel MC, Chang L, Fernandez SJ, Gong Y, Viola KL, Lambert MP, Velasco PT, Bigio EH, Finch CE, Krafft GA, Klein WL (2004) Synaptic targeting by Alzheimer's-related amyloid beta oligomers. J Neurosci 24(45):10191-10200. https://doi. org/10.1523/JNEUROSCI.3432-04.2004

LaFerla FM, Green KN, Oddo S (2007) Intracellular amyloid-beta in Alzheimer's disease. Nat Rev Neurosci 8(7):499-509. https://doi. org/10.1038/nrn2168

Lambert MP, Barlow AK, Chromy BA, Edwards C, Freed R, Liosatos M, Morgan TE, Rozovsky I, Trommer B, Viola KL, Wals P, Zhang C, Finch CE, Krafft GA, Klein WL (1998) Diffusible, nonfibrillar ligands derived from Abeta1-42 are potent central nervous system neurotoxins. Proc Natl Acad Sci USA 95(11):6448-6453. https:// doi.org/10.1073/pnas.95.11.6448

Larson J, Lynch G, Games D, Seubert P (1999) Alterations in synaptic transmission and long-term potentiation in hippocampal slices from young and aged PDAPP mice. Brain Res 840(1-2):23-35

Lasztoczi B, Tukker JJ, Somogyi P, Klausberger T (2011) Terminal field and firing selectivity of cholecystokinin-expressing interneurons in the hippocampal CA3 area. J Neurosci 31(49):1807318093. https://doi.org/10.1523/JNEUROSCI.3573-11.2011

Lee E, Choi J, Jo Y, Kim JY, Jang YJ, Lee HM, Kim SY, Lee HJ, Cho K, Jung N, Hur EM, Jeong SJ, Moon C, Choe Y, Rhyu IJ, Kim H, Sun W (2016) ACT-PRESTO: rapid and consistent tissue clearing and labeling method for 3-dimensional (3D) imaging. Sci Rep 6:18631. https://doi.org/10.1038/srep18631

Lesne S, Koh MT, Kotilinek L, Kayed R, Glabe CG, Yang A, Gallagher M, Ashe KH (2006) A specific amyloid-beta protein assembly in the brain impairs memory. Nature 440(7082):352-357. https://doi. org/10.1038/nature04533

Mably AJ, Gereke BJ, Jones DT, Colgin LL (2017) Impairments in spatial representations and rhythmic coordination of place cells in the $3 \times$ Tg mouse model of Alzheimer's disease. Hippocampus 27(4):378-392. https://doi.org/10.1002/hipo.22697

Mann EO, Paulsen O (2007) Role of GABAergic inhibition in hippocampal network oscillations. Trends Neurosci 30(7):343-349. https://doi.org/10.1016/j.tins.2007.05.003

Mann EO, Suckling JM, Hajos N, Greenfield SA, Paulsen O (2005) Perisomatic feedback inhibition underlies cholinergically induced fast network oscillations in the rat hippocampus in vitro. Neuron 45(1):105-117. https://doi.org/10.1016/j.neuron.2004.12.016

Martinez-Losa M, Tracy TE, Ma K, Verret L, Clemente-Perez A, Khan AS, Cobos I, Ho K, Gan L, Mucke L, Alvarez-Dolado M, Palop JJ (2018) Nav1.1-overexpressing interneuron transplants restore brain rhythms and cognition in a mouse model of Alzheimer's disease. Neuron 98(1):75-89. https://doi.org/10.1016/j. neuron.2018.02.029(e75)

Maurer AP, McNaughton BL (2007) Network and intrinsic cellular mechanisms underlying theta phase precession of hippocampal neurons. Trends Neurosci 30(7):325-333. https://doi. org/10.1016/j.tins.2007.05.002

McLean CA, Cherny RA, Fraser FW, Fuller SJ, Smith MJ, Beyreuther K, Bush AI, Masters CL (1999) Soluble pool of Abeta amyloid as a determinant of severity of neurodegeneration in Alzheimer's disease. Ann Neurol 46(6):860-866

Meyer-Luehmann M, Coomaraswamy J, Bolmont T, Kaeser S, Schaefer C, Kilger E, Neuenschwander A, Abramowski D, Frey P, Jaton AL, Vigouret JM, Paganetti P, Walsh DM, Mathews PM, Ghiso J, Staufenbiel M, Walker LC, Jucker M (2006) Exogenous induction of cerebral beta-amyloidogenesis is governed by agent and host. Science 313(5794):1781-1784. https://doi. org/10.1126/science. 1131864

Mikulovic S, Restrepo CE, Siwani S, Bauer P, Pupe S, Tort ABL, Kullander K, Leao RN (2018) Ventral hippocampal OLM cells control type 2 theta oscillations and response to predator odor. Nat Commun 9(1):3638. https://doi.org/10.1038/s41467-01805907-w

Mondragon-Rodriguez S, Salas-Gallardo A, Gonzalez-Pereyra P, Macias M, Ordaz B, Pena-Ortega F, Aguilar-Vazquez A, OrtaSalazar E, Diaz-Cintra S, Perry G, Williams S (2018) Phosphorylation of Tau protein correlates with changes in hippocampal theta oscillations and reduces hippocampal excitability in Alzheimer's model. J Biol Chem 293(22):8462-8472. https://doi.org/10.1074/ jbc.RA117.001187

O’Keefe J, Recce ML (1993) Phase relationship between hippocampal place units and the EEG theta rhythm. Hippocampus 3(3):317330. https://doi.org/10.1002/hipo.450030307

Palop JJ, Mucke L (2016) Network abnormalities and interneuron dysfunction in Alzheimer disease. Nat Rev Neurosci 17(12):777-792. https://doi.org/10.1038/nrn.2016.141

Palop JJ, Chin J, Roberson ED, Wang J, Thwin MT, Bien-Ly N, Yoo J, Ho KO, Yu GQ, Kreitzer A, Finkbeiner S, Noebels JL, Mucke L (2007) Aberrant excitatory neuronal activity and compensatory remodeling of inhibitory hippocampal circuits in mouse models of Alzheimer's disease. Neuron 55(5):697-711. https:// doi.org/10.1016/j.neuron.2007.07.025

Park K, Lee J, Jang HJ, Richards BA, Kohl MM, Kwag J (2020) Optogenetic activation of parvalbumin and somatostatin interneurons selectively restores theta-nested gamma oscillations and oscillation-induced spike timing-dependent long-term potentiation impaired by amyloid beta oligomers. BMC Biol 18(1):7. https:// doi.org/10.1186/s12915-019-0732-7

Phillips KG, Hardingham NR, Fox K (2008) Postsynaptic action potentials are required for nitric-oxide-dependent long-term potentiation in CA1 neurons of adult GluR1 knock-out and wild-type mice. J Neurosci 28(52):14031-14041. https://doi.org/10.1523/ JNEUROSCI.3984-08.2008 
Pike FG, Goddard RS, Suckling JM, Ganter P, Kasthuri N, Paulsen O (2000) Distinct frequency preferences of different types of rat hippocampal neurones in response to oscillatory input currents. J Physiol 529(Pt 1):205-213. https://doi.org/10.111 1/j.1469-7793.2000.00205.x

Rice HC, de Malmazet D, Schreurs A, Frere S, Van Molle I, Volkov AN, Creemers E, Vertkin I, Nys J, Ranaivoson FM, Comoletti D, Savas JN, Remaut H, Balschun D, Wierda KD, Slutsky I, Farrow K, De Strooper B, de Wit J (2019) Secreted amyloid-beta precursor protein functions as a GABABR1a ligand to modulate synaptic transmission. Science. https://doi.org/10.1126/science.aao4827

Rossant C, Kadir SN, Goodman DFM, Schulman J, Hunter MLD, Saleem AB, Grosmark A, Belluscio M, Denfield GH, Ecker AS, Tolias AS, Solomon S, Buzsaki G, Carandini M, Harris KD (2016) Spike sorting for large, dense electrode arrays. Nat Neurosci 19(4):634-641. https://doi.org/10.1038/nn.4268

Rowan MJ, Klyubin I, Cullen WK, Anwyl R (2003) Synaptic plasticity in animal models of early Alzheimer's disease. Philos Trans R Soc Lond B Biol Sci 358(1432):821-828. https://doi. org/10.1098/rstb.2002.1240

Schmid LC, Mittag M, Poll S, Steffen J, Wagner J, Geis HR, Schwarz I, Schmidt B, Schwarz MK, Remy S, Fuhrmann M (2016) Dysfunction of somatostatin-positive interneurons associated with memory deficits in an Alzheimer's disease model. Neuron 92(1):114-125. https://doi.org/10.1016/j.neuron.2016.08.034

Scott L, Feng J, Kiss T, Needle E, Atchison K, Kawabe TT, Milici AJ, Hajos-Korcsok E, Riddell D, Hajos M (2012) Agedependent disruption in hippocampal theta oscillation in amyloid-beta overproducing transgenic mice. Neurobiol Aging 33(7):1481. https://doi.org/10.1016/j.neurobiolaging.2011.12. 010(e1413-1423)

Selkoe DJ (2002) Alzheimer's disease is a synaptic failure. Science 298(5594):789-791. https://doi.org/10.1126/science.1074069

Shankar GM, Bloodgood BL, Townsend M, Walsh DM, Selkoe DJ, Sabatini BL (2007) Natural oligomers of the Alzheimer amyloidbeta protein induce reversible synapse loss by modulating an NMDA-type glutamate receptor-dependent signaling pathway. J Neurosci 27(11):2866-2875. https://doi.org/10.1523/JNEUR OSCI.4970-06.2007

Shankar GM, Li S, Mehta TH, Garcia-Munoz A, Shepardson NE, Smith I, Brett FM, Farrell MA, Rowan MJ, Lemere CA, Regan CM, Walsh DM, Sabatini BL, Selkoe DJ (2008) Amyloid-beta protein dimers isolated directly from Alzheimer's brains impair synaptic plasticity and memory. Nat Med 14(8):837-842. https:// doi.org/10.1038/nm1782

Skaggs WE, McNaughton BL, Wilson MA, Barnes CA (1996) Theta phase precession in hippocampal neuronal populations and the compression of temporal sequences. Hippocampus 6(2):149-172. https://doi.org/10.1002/(SICI)1098-1063(1996)6:2\%3c149:AIDHIPO6\%3e3.0.CO;2-K

Somogyi P, Katona L, Klausberger T, Lasztoczi B, Viney TJ (2014) Temporal redistribution of inhibition over neuronal subcellular domains underlies state-dependent rhythmic change of excitability in the hippocampus. Philos Trans R Soc Lond B Biol Sci 369(1635):20120518. https://doi.org/10.1098/rstb.2012.0518

Song J, Sun J, Moss J, Wen Z, Sun GJ, Hsu D, Zhong C, Davoudi H, Christian KM, Toni N, Ming GL, Song H (2013) Parvalbumin interneurons mediate neuronal circuitry-neurogenesis coupling in the adult hippocampus. Nat Neurosci 16(12):1728-1730. https:// doi.org/10.1038/nn.3572

Stephan A, Laroche S, Davis S (2001) Generation of aggregated beta-amyloid in the rat hippocampus impairs synaptic transmission and plasticity and causes memory deficits. J Neurosci 21(15):5703-5714

Stephan A, Laroche S, Davis S (2003) Learning deficits and dysfunctional synaptic plasticity induced by aggregated amyloid deposits in the dentate gyrus are rescued by chronic treatment with indomethacin. Eur J Neurosci 17(9):1921-1927

Taniguchi H, He M, Wu P, Kim S, Paik R, Sugino K, Kvitsiani D, Fu Y, Lu J, Lin Y, Miyoshi G, Shima Y, Fishell G, Nelson SB, Huang ZJ (2011) A resource of Cre driver lines for genetic targeting of GABAergic neurons in cerebral cortex. Neuron 71(6):995-1013. https://doi.org/10.1016/j.neuron.2011.07.026

Tomiyama T, Matsuyama S, Iso H, Umeda T, Takuma H, Ohnishi K, Ishibashi K, Teraoka R, Sakama N, Yamashita T, Nishitsuji K, Ito K, Shimada H, Lambert MP, Klein WL, Mori H (2010) A mouse model of amyloid beta oligomers: their contribution to synaptic alteration, abnormal tau phosphorylation, glial activation, and neuronal loss in vivo. J Neurosci 30(14):4845-4856. https://doi. org/10.1523/JNEUROSCI.5825-09.2010

Tong LM, Djukic B, Arnold C, Gillespie AK, Yoon SY, Wang MM, Zhang O, Knoferle J, Rubenstein JL, Alvarez-Buylla A, Huang Y (2014) Inhibitory interneuron progenitor transplantation restores normal learning and memory in ApoE4 knock-in mice without or with Abeta accumulation. J Neurosci 34(29):9506-9515. https:// doi.org/10.1523/JNEUROSCI.0693-14.2014

Tort AB, Komorowski R, Eichenbaum H, Kopell N (2010) Measuring phase-amplitude coupling between neuronal oscillations of different frequencies. J Neurophysiol 104(2):1195-1210. https://doi. org/10.1152/jn.00106.2010

Tukker JJ, Fuentealba P, Hartwich K, Somogyi P, Klausberger T (2007) Cell type-specific tuning of hippocampal interneuron firing during gamma oscillations in vivo. J Neurosci 27(31):8184-8189. https ://doi.org/10.1523/JNEUROSCI.1685-07.2007

Tukker JJ, Lasztoczi B, Katona L, Roberts JD, Pissadaki EK, Dalezios Y, Marton L, Zhang L, Klausberger T, Somogyi P (2013) Distinct dendritic arborization and in vivo firing patterns of parvalbumin-expressing basket cells in the hippocampal area CA3. J Neurosci 33(16):6809-6825. https://doi.org/10.1523/JNEUR OSCI.5052-12.2013

Veit J, Hakim R, Jadi MP, Sejnowski TJ, Adesnik H (2017) Cortical gamma band synchronization through somatostatin interneurons. Nat Neurosci 20(7):951-959. https://doi.org/10.1038/nn.4562

Verret L, Mann EO, Hang GB, Barth AM, Cobos I, Ho K, Devidze N, Masliah E, Kreitzer AC, Mody I, Mucke L, Palop JJ (2012) Inhibitory interneuron deficit links altered network activity and cognitive dysfunction in Alzheimer model. Cell 149(3):708-721. https://doi.org/10.1016/j.cell.2012.02.046

Vertes RP (2005) Hippocampal theta rhythm: a tag for short-term memory. Hippocampus 15(7):923-935. https://doi.org/10.1002/ hipo. 20118

Villette V, Poindessous-Jazat F, Simon A, Lena C, Roullot E, Bellessort B, Epelbaum J, Dutar P, Stephan A (2010) Decreased rhythmic GABAergic septal activity and memory-associated theta oscillations after hippocampal amyloid-beta pathology in the rat. J Neurosci 30(33):10991-11003. https://doi.org/10.1523/JNEUR OSCI.6284-09.2010

Walker F, Mock M, Feyerabend M, Guy J, Wagener RJ, Schubert D, Staiger JF, Witte M (2016) Parvalbumin- and vasoactive intestinal polypeptide-expressing neocortical interneurons impose differential inhibition on Martinotti cells. Nat Commun 7:13664. https:// doi.org/10.1038/ncomms 13664

Walsh DM, Selkoe DJ (2004) Deciphering the molecular basis of memory failure in Alzheimer's disease. Neuron 44(1):181-193. https://doi.org/10.1016/j.neuron.2004.09.010

Walsh DM, Klyubin I, Fadeeva JV, Cullen WK, Anwyl R, Wolfe MS, Rowan MJ, Selkoe DJ (2002) Naturally secreted oligomers of amyloid beta protein potently inhibit hippocampal long-term potentiation in vivo. Nature 416(6880):535-539. https://doi. org/10.1038/416535a 
Wang XJ, Buzsaki G (1996) Gamma oscillation by synaptic inhibition in a hippocampal interneuronal network model. J Neurosci 16(20):6402-6413

Wang J, Ikonen S, Gurevicius K, van Groen T, Tanila H (2002) Alteration of cortical EEG in mice carrying mutated human APP transgene. Brain Res 943(2):181-190

Whittington MA, Traub RD (2003) Interneuron diversity series: inhibitory interneurons and network oscillations in vitro. Trends Neurosci 26(12):676-682. https://doi.org/10.1016/j.tins.2003.09.016

Xu H, Jeong HY, Tremblay R, Rudy B (2013) Neocortical somatostatin-expressing GABAergic interneurons disinhibit the thalamorecipient layer 4. Neuron 77(1):155-167. https://doi.org/10.1016/j. neuron.2012.11.004

Yi F, Ball J, Stoll KE, Satpute VC, Mitchell SM, Pauli JL, Holloway BB, Johnston AD, Nathanson NM, Deisseroth K, Gerber DJ, Tonegawa S, Lawrence JJ (2014) Direct excitation of parvalbuminpositive interneurons by M1 muscarinic acetylcholine receptors: roles in cellular excitability, inhibitory transmission and cognition. J Physiol 592(16):3463-3494. https://doi.org/10.1113/jphys iol.2014.275453

Zar JH (1989) Statistical procedures for biological-research-a citation classic commentary on biostatistical analysis by Zar, J.H. Cc/ Agric Biol Environ 6:20-20

Zar JH (1999) Biostatistical analysis, 4th edn. Prentice Hall, Upper Saddle River
Zemankovics R, Kali S, Paulsen O, Freund TF, Hajos N (2010) Differences in subthreshold resonance of hippocampal pyramidal cells and interneurons: the role of h-current and passive membrane characteristics. J Physiol 588(Pt 12):2109-2132. https://doi. org/10.1113/jphysiol.2009.185975

Zemankovics R, Veres JM, Oren I, Hajos N (2013) Feedforward inhibition underlies the propagation of cholinergically induced gamma oscillations from hippocampal CA3 to CA1. J Neurosci 33(30):12337-12351. https://doi.org/10.1523/JNEUR OSCI.3680-12.2013

Zhang X, Zhong W, Brankack J, Weyer SW, Muller UC, Tort AB, Draguhn A (2016) Impaired theta-gamma coupling in APP-deficient mice. Sci Rep 6:21948. https://doi.org/10.1038/srep21948

Zhang H, Zhang L, Zhou D, He X, Wang D, Pan H, Zhang X, Mei Y, Qian Q, Zheng T, Jones FE, Sun B (2017) Ablating ErbB4 in PV neurons attenuates synaptic and cognitive deficits in an animal model of Alzheimer's disease. Neurobiol Dis 106:171-180. https ://doi.org/10.1016/j.nbd.2017.07.001

Publisher's Note Springer Nature remains neutral with regard to jurisdictional claims in published maps and institutional affiliations. 